\title{
DETERMINAÇÃO DA EVAPOTRANSPIRAÇÃO UTILIZANDO O MÉTODO DO BALANÇO DE ENERGIA E LISÍMETRO DE PESAGEM
}

\section{FABIANO CHAVES DA SILVA}

Engenheiro Agrônomo

Orientador: Prof. Dr. Marcos Vinícius Folegatti

\begin{abstract}
Tese apresentada à Escola Supenor de Agricultura "Luiz de Queiroz", da Universidade de São Paulo, para obtenção do título de Doutor em Agronomia, área de concentração: Irrigação e Drenagem.
\end{abstract}

PIRACICABA

Estado de São Paulo - Brasil

Maio - 2000 
Dados Internacionais de Catalogaçāo na Publicaçāo (CIP) DIVISĀO DE BIBLIOTECA E DOCUMENTAÇÃO - Campus "Luiz de Oueiroz"/USP

\section{Silva, Fabiano Chaves da}

Determinação da evapotranspiração utilizando o método do balanço de energia e lisimetro de pesagem / Fabiano Chaves da Silva. - - Piracicaba, 2000.

$72 \mathrm{p}$.

Tese (doutorado) - Escola Superior de Agricultura Luiz de Queiroz, 2000. Bibliografia.

1. Balanço de energia 2. Evapotranspiração 3. feijāo 4. Lisimetro I. Titulo 
Aos meus pais Antonio Caetano da Silva

Filho, Josefa Odete Chaves da Silva, por todo o amor

\section{OFEREÇO}

A minha querida Ana Flávia 


\section{AGRADECIMENTOS}

À Escola Superior de Agricultura "Luiz de Queiroz", da Universidade de São Paulo, especialmente ao Departamento de Engenharia Rural pelo apoio oferecido para a realização deste trabalho.

Ao Prof. Dr. Marcos Vinícius Folegatti, pela orientação e pelo apoio e confiança depositada em meu trabalho e acima de tudo pela sua amizade;

Aos professores do Departamento de Engenharia Rural, pelos ensinamentos proferidos;

Ao curso de Pós-Graduação em Irrigação e Drenagem da ESALQ/USP, pela oportunidade a mim concedida;

Aos funcionários do Departamento de Engenharia Rural, César, Davilmar, Dona Vera, Gilmar, Hélio, Sr. Antonio cuja colaboração e amizade muito contribuiu para a realização deste trabalho;

A Fundação de Amparo à Pesquisa do Estado de São Paulo (FAPESP), pela bolsa de estudo concedida e apoio financeiro para realização do trabalho;

Aos professores do Departamento de Física e Meteorologia da ESALQ/USP pelos ensinamentos e amizade, em especial ao Prof. Nilson Augusto Villa Nova pessoa pela qual tenho satisfação em chamar de amigo;

A minha querida amiga Marina por todo seu carinho e amizade.

Aos amigos, em especial a Alexandre Bryan e Giovana, Luis Fernando e Nádia, Raquel Furlan, Leonardo e Glenda, Adriana e Tedy, Carmelo e Juliana, Thales, Valdemicio, Cecília e Axel, Rene, pelo apoio e amizade;

Ao companheiro Vital Pedro da Silva, Prof. Titular da Escola de Agronomia da UFBA, pelo apoio e amizade;

Ao Prof. Francisco Adriano da Escola de Agronomia da UFBA, pelo exemplo de profissionalismo e dedicação ao ensino;

A Raquel Trevizam por sua presença em minha vida.

A todos aqueles que contribuíram para a realização deste trabalho. 


\section{SUMÁRIO}

Página

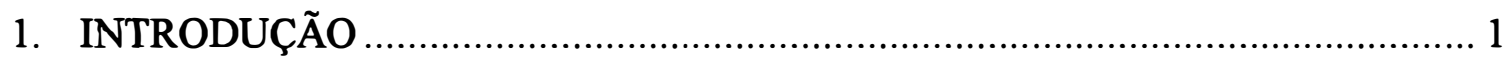

2. REVISÃO DE LITERATURA .............................................................. 3

2.1. Crescimento e desenvolvimento do feijoeiro .......................................... 3

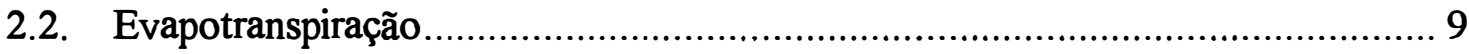

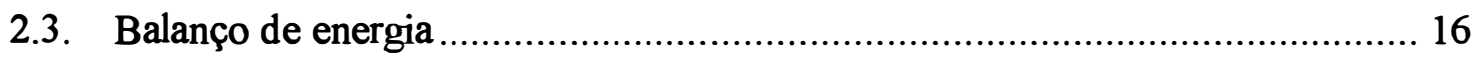

3. BALANÇO DE ENERGIA NA CULTURA DE FEIJÃO UTILIZANDO UM SISTEMA DE RAZÃO DE BOWEN ................................................... 25

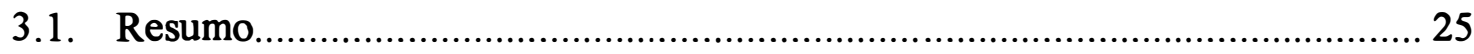

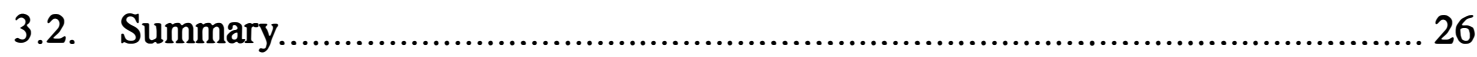

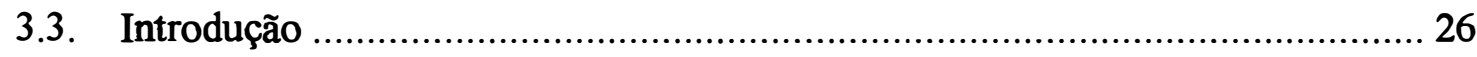

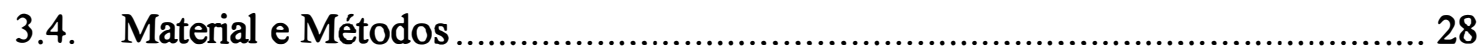

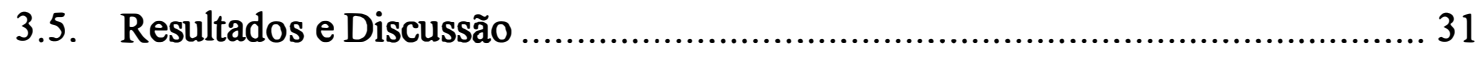

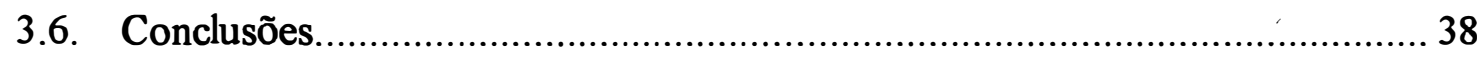

4. RELAÇÃO ENTRE A RADIAÇÃO SOLAR E RADIAÇÃO LÍQUIDA SOBRE

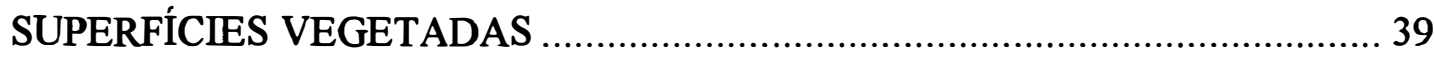

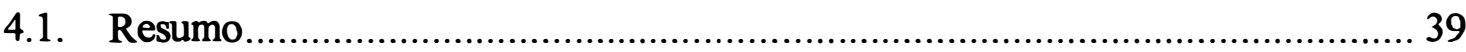

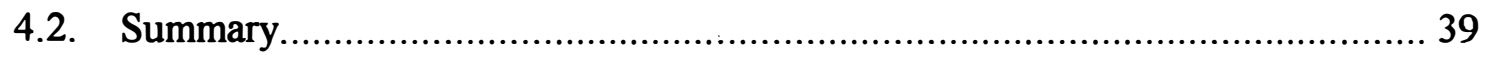

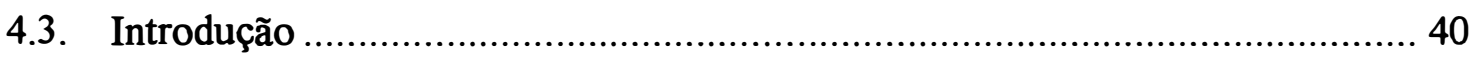

4.4. Material e Métodos ....................................................................... 42

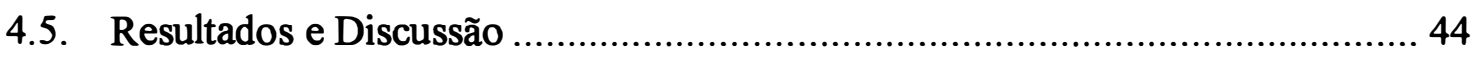




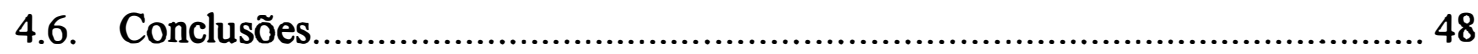

5. EVAPOTRANSPIRAÇÃO DO FEIJOEIRO (PHASEOLUS VULGARIS L.) E EVAPOTRANSPIRAÇÃO DE REFERÊNCIA DETERMINADAS PELOS MÉTODO DO BALANÇO DE ENERGIA E LISÍMETRO DE PESAGEM......... 49

5.1. Resumo

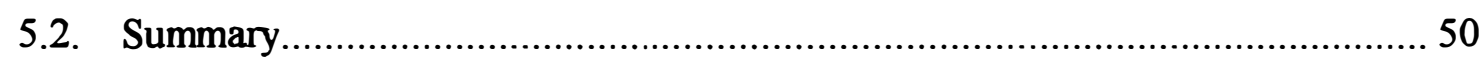

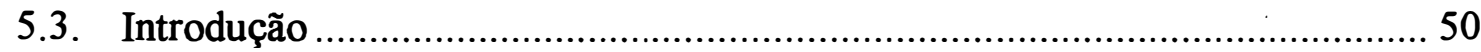

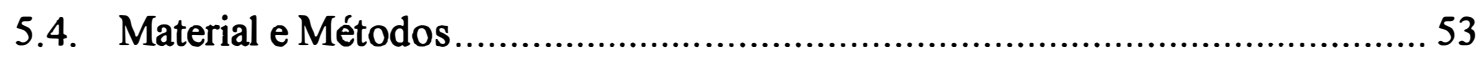

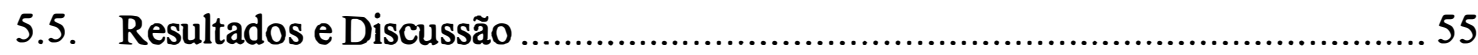

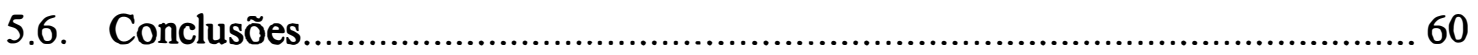

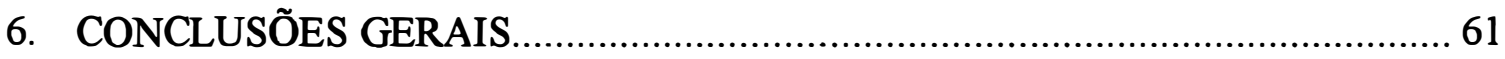

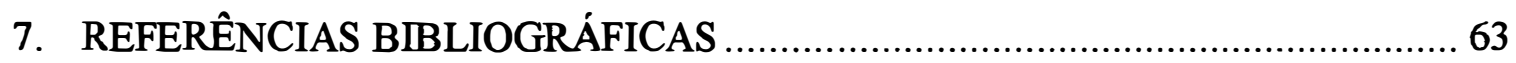




\section{LISTA DE SÍMBOLOS}

\begin{tabular}{|c|c|c|}
\hline SÍMBOLO & DESCRIČÃO & UNDADE \\
\hline ETo & Evapotranspiração de referência & $\mathrm{mm}$ \\
\hline ETa & Evapotranspiração real & $\mathrm{mm}$ \\
\hline ETc & Evapotranspiração da cultura & $\mathrm{mm}$ \\
\hline ET & Evapotranspiração & $\mathrm{mm}$ \\
\hline Kc & Coeficiente de cultura & \\
\hline ETr & Evapotranspiração de referência da alfafa & $\mathrm{mm}$ \\
\hline IAF & Índice de área foliar & \\
\hline${ }^{\circ} \mathbf{C}$ & Grau centigrado & ${ }^{\circ} \mathrm{C}$ \\
\hline I & Irrigação & 1 \\
\hline D & Drenagem & 1 \\
\hline$\Delta \mathbf{s}$ & Variação de armazenamento & \\
\hline LE & Fluxo de calor latente de evaporação & $\mathrm{kJ} \cdot \mathrm{m}^{-2} \cdot \mathrm{s}^{-1}$ \\
\hline $\mathbf{R n}$ & Radiação líquida & $\mathrm{kJ} \cdot \mathrm{m}^{-2} \cdot \mathrm{s}^{-1}$ \\
\hline $\mathbf{G}$ & Fluxo de calor no solo & $\mathrm{kJ} \cdot \mathrm{m}^{-2} \cdot \mathrm{s}^{-1}$ \\
\hline$\rho$ & Densidade atmosférica & $\mathrm{kg} \cdot \mathrm{m}^{-3}$ \\
\hline cp & Calor específico do ar & $\begin{array}{l}\mathrm{kj} \\
{ }^{\circ} \mathrm{C}^{-1}\end{array} \mathrm{~kg}^{-1}$ \\
\hline es & Pressão de saturação de vapor à temperatura do ar & $\mathrm{kPa}$ \\
\hline ea & Pressão atual de vapor & $\mathrm{kPa}$ \\
\hline rc & resistência da cobertura vegetal & $\mathbf{s} \cdot \mathrm{m}^{-1}$ \\
\hline ra & resistência aerodinâmica à difusão de calor sensível e de calor latente & $\mathbf{s} \cdot \mathrm{m}^{-1}$ \\
\hline$\gamma$ & Constante psicrométrica & $\mathrm{kPa} \cdot{ }^{\circ} \mathrm{C}^{-1}$ \\
\hline $\mathbf{s}$ & Inclinação da curva de pressão de saturação à temperatura do ar & $\mathrm{kPa} \cdot{ }^{\circ} \mathrm{C}^{-1}$ \\
\hline$\lambda$ & Calor latente de vaporização & $\mathrm{Mj} \cdot \mathrm{kg}^{-1}$ \\
\hline $\mathbf{T}$ & Temperatura do ar & ${ }^{\circ} \mathrm{C}$ \\
\hline $\mathbf{P}$ & Pressão atmosférica & $\mathrm{kPa}$ \\
\hline DJ & Dia Juliano & \\
\hline g & Aceleração da gravidade & $\mathrm{m} \cdot \mathrm{s}^{-2}$ \\
\hline $\mathbf{R}$ & Constante universal dos gases & $\underset{{ }^{o} \mathrm{~K}^{-1}}{\mathrm{~J}} \mathrm{~kg}^{-1}$ \\
\hline To & Temperatura absoluta do ar & ${ }^{\circ} \mathrm{C}$ \\
\hline$\alpha$ & Gradiente adiabático do ar saturado & \\
\hline$\varepsilon$ & $\begin{array}{l}\text { Razão entre o peso molecular do vapor d'água e do ar atmosférico } \\
\text { seco }\end{array}$ & ${ }^{0} \mathrm{C}^{-1} \cdot \mathrm{kg}^{-1}$ \\
\hline UR & Umidade relativa do ar & $\%$ \\
\hline
\end{tabular}


k Constante de Von Karman

Uz Velocidade do vento média $\mathrm{m} \cdot \mathrm{s}^{-1}$

he altura da cultura m

$\mathrm{Kp} \quad$ Coeficiente do tanque

ECA Evaporação do tanque "Classe A" $\mathrm{mm}$

EtoCA Estimativa da evapotranspiração de referência pelo método do tanque $\mathrm{mm}$

P Massa específica do ar atmosférico $\mathrm{kg} \mathrm{m}^{-3}$ 


\title{
DETERMINAÇÃO DA EVAPOTRANSPIRAÇÃO UTILIZANDO O MÉTODO DO BALANÇO DE ENERGIAE LISÍMETRO DE PESAGEM
}

\author{
Autor : FABIANO CHAVES DA SILVA \\ Orientador : MARCOS VINÍCIUS FOLEGATTI
}

\section{RESUMO}

Este trabalho teve como objetivo à aplicação do método do balanço de energia para a determinação da evapotranspiração da cultura do feijão (Phaseolus vulgaris L.) e da evapotranspiração de referência, e compará-las aos dados medidos em lisímetro de pesagem; Determinação do coeficiente de cultura para os diferentes estádios de desenvolvimento da cultura e; Estudar as relações entre a radiação solar e líquida sobre superfícies vegetadas pela cultura do feijão e da grama batatais (Paspalum notatum

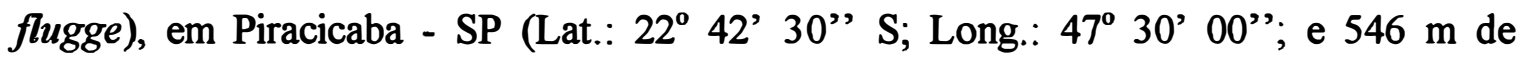
altitude). Para tanto, foram utilizadas medidas de ET obtidas em lisímetro de pesagem automatizado com células de carga e através do sistema automático de razão de Bowen, no período de 13 de agosto a 12 de novembro de 1998. Os dados foram coletados diariamente e analisados estatisticamente mediante análise de regressão. Com base nos resultados verificou-se que os valores de evapotranspiração diários e horários da cultura do feijão (Phaseolus vulgaris L.), medidos pelo método do Balanço de energia foram altamente correlacionados com as medidas feitas em lisímetro de pesagem. A evapotranspiração da cultura do feijão na localidade de Piracicaba - SP foi de 4,36 mm.dia ${ }^{-1}$, ou 130,82 mm para o período de observação e, $5,05 \mathrm{~mm} \cdot$ dia $^{-1}$ ou 151,36 mm, respectivamente, pelo método do balanço de energia e lisímetro de pesagem. A evapotranspiração de referência (ETo) obtida para o mesmo período sobre uma superficie gramada apresentou valores $5,19 \mathrm{~mm} \cdot \mathrm{dia}^{-1}$ e $155,66 \mathrm{~mm}$ no total utilizando o método do Balanço de energia; o lisímetro de pesagem apresentou um valor médio de ETo igual a 
$6,22 \mathrm{~mm} \cdot \mathrm{dia}^{-1} \mathrm{e}$ um total de $186,63 \mathrm{~mm}$. Os coeficientes de cultura médios $(\mathrm{Kc})$ foram 0,85 e 0,84 para todo o ciclo, respectivamente, baseados no método do Balanço de energia e do lisímetro de pesagem. De maneira geral, o valor de $\mathrm{Kc}_{\text {Bowen }} \mathrm{e} \mathrm{Kc}_{\text {lisimetro não }}$ apresentaram diferença significativa. Os métodos de regressão linear de estimativa da Rn para fins elaboração de projetos de irrigação obtidos pela relação $\mathrm{Rn}=0,6069 \mathrm{Qg}$ para uma superficie gramada (Paspalum notatum flugge) e $\mathrm{Rn}=0,6817 \mathrm{Qg}$ para uma superficie vegetada pela cultura do feijão (Phaseolus vulgaris L.) podem ser recomendadas. 


\title{
DETERMINATION OF EVAPOTRANSPIRATION USING THE ENERGY BALANCE METHOD AND WEIGHING LYSIMETER
}

\author{
Author : FABIANO CHAVES DA SILVA \\ Adviser : MARCOS VINICIUS FOLEGATTI
}

\section{SUMMARY}

The objectives of the present work were the bean (Phaseolus vulgaris L.) crop evapotranspiration and the reference evapotranspiration determinations, by energy balance method and then, the comparison of the data obtained, by the weighing lysimeter; The crop coefficient determination for different crop growth stages and, finally, to study the relations between the solar and net radiation on the bean crop and on area vegetated with grass (Paspalum notatum flugge) areas, in Piracicaba - SP $\left(22^{\circ} 42^{\prime} 30^{\prime \prime}\right.$ south latitude, $47^{\circ} 30^{\prime} 00^{\prime \prime}$ west longitude and $546 \mathrm{~m}$ of altitude). For these purposes, ET measures were obtained by automatic weighing lysimeter with load cells, and by using the automatic Bowen ratio system, during August 13th to November 12th, 1998. The data were collected and analyzed, statistically, through regression analysis. According to the results, the daily and the hourly bean crop evapotranspiration values measured by the Energy Balance method were highly correlated with the measures obtained by the weighing lysimeter. The bean crop evapotranspiration values in Piracicaba -SP were: 4,36 $\mathrm{mm}$.day ${ }^{-1}$ or $130 \mathrm{~mm}$ during the whole analyzed period and $5,05 \mathrm{~mm} \cdot$ day $^{-1}$ or $151,36 \mathrm{~mm}$, by the Bowen ratio method and weighing lysimeter, respectively. The reference evapotranspiration (ETo) obtained during the same period showed the following values: 5,19 mm.day ${ }^{-1}$ and 155,66 mm (total) using the Bowen ratio method; and 6,22 mm.day ${ }^{-1}$ and $186,63 \mathrm{~mm}$ during the whole period, when the weighing lysimeter was employed. The mean crop coefficient $(\mathrm{Kc})$ values were 0,85 and 0,84 for the whole growth season, 
respectively, based on Energy Balance method and weighing lysimeter. In general, the Kc Bowen and the Kc lysimeter didn't show significant differences. The linear regression methods of $\mathrm{Rn}$ estimation, in a view to elaborate irrigation projects, obtained by the relation $\mathrm{Rn}=0,6069 \mathrm{Qg}$ for area vegetated with grass area (Paspalum notatum flugge) and $\mathrm{Rn}=0,6817 \mathrm{Qg}$ for a bean crop area (Phaseolus vulgaris $\mathrm{L}$.) may be recommended. 


\section{INTRODUÇÃO}

A evapotranspiração pode ser obtida de diferentes maneiras: de forma indireta, a partir de fórmulas teóricas ou empíricas que utilizam dados do solo; dados meteorológicos e indicadores das plantas e por meio de medidas diretas através do balanço hídrico do solo e lisímetros.

Os métodos indiretos, que se baseiam no solo, consideram-no como um reservatório capaz de conter certa quantidade de água. Os métodos meteorológicos utilizam basicamente informações meteorológicas como entradas para modelos que calculam a quantidade de água evapotranspirada pela cultura durante um certo período de tempo. Métodos baseados em indicadores da planta podem ser mais adequados uma vez que a planta responde às condições atmosféricas e do solo. Parâmetros como temperatura da cobertura vegetal, potencial de água na folha, variações do diâmetro de caules e frutos estão sendo estudados. A utilização de modelos baseados no clima ou na comunidade vegetal, implica em sua calibração e adequação para as condições locais específicas.

A determinação da evapotranspiração, por meio de medidas em lisímetros é uma operação de dificil execução em condições de campo. Visando abreviar essa dificuldade, vários pesquisadores procuraram desenvolver métodos de estimativa da evapotranspiração relacionando a perda de água de superficies naturais com dados meteorológicos mais facilmente disponíveis. 
Estimativas meteorológicas do fluxo de água na atmosfera podem prover valores representativos da evapotranspiração. $\mathrm{O}$ maior obstáculo deste tipo de mensuração é a disponibilidade, o custo e a facilidade de instalação e operação dos instrumentos. Com o recente desenvolvimento da tecnologia em sensores e sistemas de aquisição de dados, é possível mensurar de forma direta e em tempo real a evapotranspiração com um custo relativamente baixo.

$\mathrm{O}$ balanço de energia das superficies vegetadas permite dimensionar as trocas de massas e energia no sistema solo-planta-atmosfera, através do estudo da participação do saldo de radiação nos diversos processos que ocorrem na cultura. $\mathbf{O}$ método permite avaliar as alterações no microclima da vegetação em função dos estádios de desenvolvimento da cultura e em função das condições do solo e da atmosfera.

Em virtude do exposto, desenvolveu-se o presente trabalho, com os seguintes objetivos:

a) Aplicação do método do Balanço de energia para a determinação da Evapotranspiração da Cultura do feijão (Phaseolus vulgaris L.) e da Evapotranspiração de Referência, comparando aos dados medidos em lisímetro de pesagem;

b) Determinação do coeficiente de cultura para os diferentes estádios de desenvolvimento da cultura;

c) Estudar as relações entre a radiação solar e líquida sobre superficies vegetadas pela cultura do feijão e da grama batatais (Paspalum notatum flugge). 


\section{REVISÃO DE LITERATURA}

\subsection{Crescimento e desenvolvimento do feijoeiro}

Para a população do Brasil o feijão é importante fonte de proteína e calorias. $\mathbf{O}$ cultivo do feijoeiro é praticado em todo o território nacional nos mais diversificados tipos de solo, climas e sistemas de produção.

O mercado consumidor não se mostra saturado e a maioria dos produtores pode contar com grande potencial para altas produtividades e redução dos custos. $\mathbf{O}$ aumento do número de produtores que utilizam a irrigação e aproveitam a sazonalidade da produção para obter melhores preços, permite esperar que, em médio prazo, o abastecimento melhore. Atualmente os investimentos em tecnologia são viáveis especialmente em áreas onde a falta de chuvas na época de colheita promove riscos de perdas (Agrianual, 1998).

Os baixos rendimentos da cultura do feijoeiro no Brasil são causados pela utilização inadequada de tecnologias ou de processos. Apesar da pesquisa já dispor de resultados com capacidade para triplicar a produtividade atual, são insignificantes os avanços obtidos, de modo que, na maioria dos casos a produção nacional ainda é conduzida predominantemente por pequenos produtores que, por questões socioeconômicas, não se adequam a novas tecnologias.

O feijoeiro é uma leguminosa anual, herbácea, de hábito de crescimento determinado ou indeterminado e duração média do ciclo variando de 80 a 110 dias. Seu desenvolvimento é acentuadamente dependente de condições climáticas favoráveis, como 
temperatura entre 15 e $27^{\circ} \mathrm{C}$ e precipitação pluvial mensal de cerca de 100 a $150 \mathrm{~mm}$ (Vieira, 1978 e Bulisani et al. 1987). É uma planta $C_{3}$, saturando-se fotossinteticamente a intensidade de luz relativamente baixa (White, 1988; Portes, 1996). Devido a este fato podem ocorrer limitações consideráveis no cultivo do feijoeiro em regiões tropicais e subtropicais, em relação aos processos de fotossíntese, respiração, aproveitamento de água, competitividade, saturação lumínica e fotorrespiração (Fancelli, 1990). As espécies mais utilizadas são Phaseolus vulgaris L. e Vigna ungulata, comumente encontrados nos mais variados tamanhos e diferentes cores.

O ciclo biológico do feijoeiro é caracterizado por duas fases distintas: a vegetativa e a reprodutiva. Estas compreendem diferentes estádios de desenvolvimento, com diferenciações morfo-fisológicas. Não são fisiologicamente bem separadas, particularmente naquelas plantas de hábito de crescimento indeterminado, possibilitando à espécie, pela sobreposição das mesmas, a produção simultânea de folhas, flores e vagens (Fernández et al. 1982; Geptz \& Fernández 1982).

A fase vegetativa do feijoeiro tem seu início na germinação da semente, prosseguindo até o aparecimento dos primeiros botões florais. Esta fase é favorecida pela ocorrência de temperaturas moderadamente elevadas, entre 21 e $29,5^{\circ} \mathrm{C}$, disponibilidade hídrica adequada e luminosidade abundante. Já a fase reprodutiva é delimitada pela emissão de botões florais, pleno enchimento de vagens e maturidade das sementes (Fernández et al. 1982).

Gepts \& Fernández (1982) propuseram a utilização de uma escala fenológica para o feijoeiro em que o ciclo dessa leguminosa é constituído por dez estádios de desenvolvimento, identificados por um código de letras $(\mathrm{V}=$ fase vegetativa e $\mathrm{R}=$ fase reprodutiva) e combinadas com coeficientes ( 0 a 9) que indicam a posição da etapa de desenvolvimento da planta na escala. A duração dessas etapas pode ser afetada por diversos fatores, tais como: genótipo, determinante do hábito de crescimento e da 
precocidade; o clima, incluindo a luminosidade; e, propriedades fisicas e químicas do solo e sua umidade.

$\mathrm{O}$ estádio $\mathrm{V}_{0}$ (germinação) caracteriza-se pelo aparecimento da radícula, seguido pela elongação do hipocótilo e finalizando com o aparecimento dos cotilédones na superficie do solo. Essa fase é sensível à falta de água e segundo Magalhães \& Carelli (1972), valores de tensão da água no solo superiores a 3,5 atm podem reduzir drasticamente a germinação e a elongação das células.

No estádio $V_{1}$ (emergência) os cotilédones encontram-se acima da superficie do solo, com a alça do hipocótilo em fase de desdobramento. Há o alongamento do epicótilo e a expansão das folhas primárias.

Em $\mathrm{V}_{2}$ (emissão da primeira folha trifoliada) verifica-se a completa expansão das folhas primárias, sendo que o seu tamanho potencial está relacionado ao tamanho das sementes.

$\mathrm{O}$ estádio $\mathrm{V}_{3}$ (emissão da primeira folha trifoliolada) inicia-se quando a primeira folha verdadeira ou trifoliolada está completamente desdobrada e na posição horizontal. Nessa fase, os cotilédones encontram-se exauridos e, em geral, há a sua abscisão. A partir desse ponto, observa-se um rápido desenvolvimento vegetativo da planta, a qual passa a depender diretamente dos nutrientes disponíveis no solo. No período entre os estádios $V_{0}$ e $V_{3}$ a planta de feijoeiro é mais tolerante a estresses hídricos e baixas temperaturas, desde que em níveis moderados. Segundo Caixeta (1978), o consumo de água pelo feijoeiro quase nunca excede $3,0 \mathrm{~mm} \cdot \mathrm{dia}^{-1}$ nessas fases.

No estádio $\mathrm{V}_{4}$ (emissão da terceira folha trifoliada) a terceira folha trifoliada está completamente expandida e o ritmo de desenvolvimento vegetativo é máximo. Nesse período, segundo Fancelli \& Dourado-Neto (1997), a ocorrência de deficiência hídrica pode reduzir drasticamente a altura e o índice de área foliar do feijoeiro, com 
conseqüente efeito restritivo à produtividade da cultura. $\mathbf{O}$ consumo de água pode variar entre 4,0 a 4,5 mm.dia ${ }^{-1}$ (Caixeta, 1978).

$\mathrm{O}$ estádio $\mathrm{R}_{5}$ (pré-florescimento ou início da fase reprodutiva) se inicia pelo aparecimento dos primeiros botões florais. Esta fase do desenvolvimento do feijoeiro é considerada uma das mais críticas à deficiência de água, segundo diversos autores citados por Fancelli \& Dourado-Neto (1997). Em decorrência de um possível estresse hídrico pode haver suspensão brusca da emissão de novas folhas nas plantas de hábito de crescimento indeterminado, com perdas de produtividade entre 15 até $30 \%$ (Fancelli \& Dourado-Neto, 1997). O consumo de água nessa fase varia entre 4,0 a 4,5 mm.dia ${ }^{-1}$, podendo exceder a $5 \mathrm{~mm}$. dia ${ }^{-1}$ quando as condições ambientais forem de intenso calor e baixa umidade relativa do ar (Caixeta, 1978).

$O$ estádio $R_{6}$ (florescimento) se inicia pelo aparecimento das primeiras flores, correspondentes aos primeiros botões florais. A queda natural de flores pode variar de $40 \%$ a $75 \%$ em função das condições climáticas vigentes no período (Fancelli \& Dourado-Neto, 1997).

O consumo de água pelo feijoeiro nessa fase pode variar entre 4,0 mm.dia ${ }^{-1}$ a 4,5 $\mathrm{mm} \cdot \mathrm{dia}^{-1}$, sendo que a ocorrência de períodos de falta de água por cerca de uma semana poderá acarretar redução de $48 \%$ no rendimento (Garrido et al. 1979). Por outro lado, o excesso de água pode colaborar igualmente para a redução do rendimento em $48 \%$ a 68 $\%$, se a situação de encharcamento do solo se prolongar por dois a seis dias (Silva, 1982).

Em $R_{7}$ (formação de vagens), a planta apresenta a primeira vagem com a corola da flor murcha e desprendida, observando-se, ainda, a emissão de novas flores. Esse estádio finaliza quando as vagens atingem seu tamanho final e peso máximo, iniciando-se o seu enchimento (Fernández et al. 1982). Esta fase é extremamente sensível à deficiência hídrica, podendo provocar a diminuição da produtividade pela redução da fotossíntese e do metabolismo (Fancelli \& Dourado-Neto, 1997). Essa diminuição na produtividade foi 
de $58 \%$ no período efetivo de formação de vagens, conforme observado por Garrido et al. (1979). O consumo de água pelo feijoeiro durante essa fase pode variar entre 4,0 mm.dia ${ }^{-1}$ a 4,5 mm.dia ${ }^{-1}$, chegando a exceder $5 \mathrm{~mm} \cdot \mathrm{dia}^{-1} \mathrm{em}$ condições de intenso calor $\mathrm{e}$ baixa umidade relativa (Caixeta, 1978).

$O$ estádio $R_{8}$ (enchimento de vagens) se inicia pelo enchimento da primeira vagem, que já se encontrava em seu tamanho definitivo, seguido pelo crescimento ativo das sementes e finalizando pela alteração na coloração da semente e, em seqüência, da vagem. Ao final dessa fase observa-se um amarelecimento e início de abscisão das folhas inferiores e, ainda emissão de novas folhas pelas plantas de hábito de crescimento indeterminado (Fernández et al. 1982). A ocorrência de estresse hídrico e também nutricional pode reduzir bastante o número e o peso das sementes e, portanto, a produtividade (Fancelli \& Dourado-Neto, 1997). O consumo de água nessa fase pode variar entre $4,0 \mathrm{~mm} \cdot \mathrm{dia}^{-1}$ a $4,5 \mathrm{~mm} \cdot \mathrm{dia}^{-1}$.

O estádio $R_{9}$ (maturidade das vagens) é a última fase de desenvolvimento do feijoeiro, caracterizando-se pela alteração na coloração das vagens (para amarelada ou pigmentada, conforme o cultivar) e em seu teor de água. Este também se reduz até $15 \%$ nas sementes, que então adquirem sua coloração final. $O$ processo de senescência da planta se acentua com o amarelecimento e queda abundantes das folhas. $\mathrm{O}$ ciclo biológico da planta se encerra e a cultura pode então ser colhida (Fernández et al. 1982). Nessa etapa do desenvolvimento a necessidade em água é quase nula.

$\mathrm{O}$ índice de área foliar (IAF) é uma medida de área foliar correspondente à superficie de tecido foliar produzida sobre determinada área de solo. A área foliar é uma característica genética, no entanto, pode ser modificado pela densidade populacional e pela aplicação de água e de fertilizantes (Yoshida, 1972). A produção de matéria seca é função do IAF até um determinado valor. Brougham (1958) observou um aumento de produção até um certo valor do IAF, por ele denominado de "crítico", correspondendo àquele em que há interceptação de $95 \%$ da luz solar incidente ao meio dia. 
Resende et al. (1981) e Stone et al. (1988) observaram que o IAF no florescimento foi bastante afetado pelos níveis de estresse hídrico. Guimarães (1992) observou resultados similares com reduções de $11,6 \%$ e $45,5 \%$ no IAF do cultivar Carioca, sob estresse de moderado a severo, respectivamente.

Portes (1996) relatou valores experimentais de IAF variando de 0,75 a 2,20 e de 0,80 a 4,00 , respectivamente, durante o ciclo das plantas de feijoeiro dos cultivares Carioca e Aporé, ambos de hábito de crescimento indeterminado do tipo III, submetidos ou não a adubações nitrogenadas foliares dos 25 dias até o final do florescimento. Para os dois cultivares o máximo valor de IAF foi observado ao redor do 55 dias do ciclo, declinando rapidamente a partir do $85^{\circ}$ dia.

O emprego de coeficientes relacionando a evapotranspiração da cultura e parâmetros meteorológicos de referência permitem a comparação ou a reprodução dos valores em outros locais e épocas.

Para o caso do feijoeiro, Doorenbos \& Pruitt (1977) citaram que o consumo total de água acumulado varia entre $250 \mathrm{~mm}$ a $400 \mathrm{~mm}$, em função da interação de diversos fatores, variando de 0,85 a 1,05 a relação entre a evapotranspiração da cultura e a evapotranspiração de referência baseada no tanque "Classe $A$ ", da metade ao final do ciclo.

Doorenbos e Pruitt (1977) citam que a evapotranspiração total, acumulada ao longo do ciclo de uma cultura, varia de acordo com os seguintes fatores: características das plantas e do seu manejo, condições atmosféricas, disponibilidade de água no solo e tamanho da área cultivada. Em função da variação destes fatores, os valores absolutos de consumo de água para uma mesma espécie cultivada encontrados na literatura diferem bastante. $\mathrm{O}$ consumo de água pela cultura do feijoeiro varia de acordo com o estado de desenvolvimento, com a variedade, com o local, com as condições de solo e com a época de plantio. 
O feijoeiro é sensível tanto à deficiência quanto ao excesso de água no solo, principalmente nas fases de florescimento e de desenvolvimento das vagens. $\mathrm{O}$ consumo de água pela cultura varia basicamente com o estádio de desenvolvimento, cultivar e condições climáticas locais. Em geral, o consumo total de água pode variar entre $300 \mathrm{~mm}$ a $500 \mathrm{~mm}$ por ciclo, quando cultivado sob sistema de preparo de solo convencional e de $250 \mathrm{~mm}$ a $400 \mathrm{~mm}$ sob plantio direto (Moreira \& Stone, 1995).

O consumo de água do feijoeiro tem sido avaliado por vários pesquisadores. Para Luchiari Júnior (1978) a evapotranspiração real média da cultura do feijão na época seca é de 3,06 mm. dia ${ }^{-1}$ da germinação à fase de maturação. Saad (1991) observou em GuairaSP, que a evapotranspiração média em 80 dias do ciclo da cultura foi de $3,38 \mathrm{~mm}$. Reichardt et al. (1974) utilizando o método do balanço hídrico, registraram para as condições de Piracicaba - SP, uma evapotranspiração média de $3,45 \mathrm{~mm}$. dia ${ }^{-1}$ durante 48 dias do ciclo.

\subsection{Evapotranspiração}

A água é elemento essencial ao metabolismo vegetal, pois participa principalmente de sua constituição e do processo de fotossíntese. A planta transfere para a atmosfera cerca de $98 \%$ da água retirada do solo. Por isto, o consumo de água das plantas normalmente se refere à água evaporada da superficie do solo e transpirada.

A evapotranspiração é função dos elementos meteorológicos, do solo e da planta (Lemon et al, 1957). Penman (1956) argumenta que quando a cobertura do solo é completa, a ETo é condicionada principalmente pelos elementos meteorológicos. A radiação líquida é o principal elemento meteorológico, que influencia a evapotranspiração (Pelton et al, 1960; Tanner \& Lemon, 1962; Villa Nova et al, 1976). A importância relativa da radiação líquida, da umidade relativa do ar e da velocidade do vento na ETo é 
da ordem de 80:6:14 respectivamente (Mukammal \& Bruce ${ }^{1}$, citado em Berlato \& Molion, 1981). Villa Nova (1987) ressalta que é dificil separar a ação de cada um destes elementos, pois os mesmos agem simultaneamente. Assim, de uma maneira geral, para uma dada região, quanto maior for a disponibilidade de energia solar, temperatura do ar e velocidade do vento, e quanto menor for a umidade relativa do ar, maior deverá ser a taxa de evapotranspiração. Entretanto, em regiões onde ocorrem advecções fortes, condição que comumente incide quando uma área úmida é circundada por uma área seca, a importância relativa da radiação líquida decresce e, em adição a radiação líquida, a advecção ou transferência de calor sensível das áreas secas circunvizinhas, poderá contribuir no processo evapotranspirativo com energia até maior que aquela disponível à área úmida, aumentando desta forma a importância da velocidade do vento e umidade relativa do ar na evapotranspiração.

A advecção é definida como a troca de energia, umidade ou "momentum" devido à heterogeneidade horizontal. Millar (1964) trabalhando com um campo irrigado de Trifolium repens $L$. concluiu que a advecção ocasiona um consumo de calor latente superior ao suprimento de radiação local para uma considerável faixa após a interface seco/úmido e que houve um decréscimo da evaporação à medida que se afastava da interface seco/úmido. Pelton et al. (1960) denominou-a "efeito varal”. À medida que se afastava da interface, dependendo do tamanho da área tampão, a evapotranspiração decresce e pode atingir a evapotranspiração potencial. $O$ tamanho da área tampão dependerá das condições locais. Resultados de Goltz \& Pruit ${ }^{2}$ (1970), citados por Pereira (1990), trabalhando em condições semi-áridas de Davis, Califórnia, concluem que o tamanho adequado para minimizar-se o efeito advectivo seria maior que 100 metros, para um campo cultivado com grama rasteira. Para condições áridas de Israel, Stanhill (1961) mostra que para um campo de alfafa o tamanho passaria a $300 \mathrm{~m}$.

\footnotetext{
${ }^{1}$ MUKAMAL, E. I.; BRUCE, J. P. Evaporation measurements by pan and atmometer. Intemational Union of Geodesy an geophysics. Association od Scientific hydrology, 53: 408-20 apud CHANG, JEN-HU. 1968. Climate and agriculture: an ecological survey. Chicago, Aldine.
} 
Segundo Rosenberg \& Verma (1978), em regiões úmidas, a energia consumida pela evaporação raramente excede a radiação líquida. No entanto, em condições semiáridas e áridas o fluxo de calor latente excede o da radiação líquida. $\mathrm{O}$ calor sensível que é consumido é trazido por advecção de locais secos. Os autores mostraram que para a região na qual foi desenvolvido o trabalho, em dias limpos as taxas de evapotranspiração foram de 8 a $12 \mathrm{~mm}$, sendo que a energia líquida era suficiente para 6 ou $7 \mathrm{~mm}$ de evapotranspiração, confirmando a influência da advecção local, no período considerado.

É necessário conhecimento minucioso de certas definições, quando se trata da quantificação da evapotranspiração e do requerimento de água das culturas. Mensurações históricas têm sido realizadas sob diferentes condições e os dados resultantes assumem diferentes conceitos. Comparações e interpretação de dados de evapotranspiração dependem sobretudo de um uso acurado das definições. Por exemplo, um incorreto conhecimento das definições pode levar a um intercâmbio de dados e métodos de estimativa não compatíveis (Jensen, 1991).

A evaporação da água é um fenômeno fisico que propicia a mudança de estado da água da fase líquida para a gasosa diretamente de uma superficie líquida (mar, lago, rio, etc) ou úmida (planta, solo). Quando esta mudança se dá através das plantas recebe o nome de transpiração. No caso de solos parcialmente vegetados estes processos ocorrem simultânea e interdepedentemente, daí a utilização do termo evapotranspiração (Berlato \& Molion, 1981).

Thornthwaite (1948) introduziu na literatura o termo evapotranspiração potencial (ETp), definindo-a como sendo "a quantidade de água utilizada por uma extensa área vegetada, em crescimento ativo, sob condições ótimas de umidade do solo".

\footnotetext{
${ }^{2}$ GOLTZ, S. M.; PRUTTT, W. O. Spatial and temporal variations of evapotranspiration downwind from a trailing of a dry fallow field. In : MORGAN, D. L.; PRUITT, W. O.; LOURENCE, F. J. Evaporation from an irrigated turf under advection of dry air at Davis, California. Davis: Univerity of Califormia, 1970. 70p.
} 
Penman (1956) definiu evapotranspiração potencial como "a quantidade de água utilizada na unidade de tempo por uma cultura de porte baixo e verde, cobrindo totalmente a superficie, com altura uniforme e sem deficiência hídrica". Culturas de porte baixo estão implícitas nesta definição, no entanto, Penman aplicou esse conceito às gramas de porte baixo. A evapotranspiração de culturas irrigadas pode ser de 10 a $30 \%$ maior do que a ocorrida em superficie gramada.

Quando as condições de contorno acima não forem verificadas tem-se a evapotranspiração real (ETa), que é aquela que ocorre em uma superficie vegetada, independente de sua área e das condições de umidade do solo (Thornthwaite, 1948; Camargo,1961; Sediyama, 1987; Villa Nova \& Reichardt, 1989; Pereira, 1992).

O conceito de evapotranspiração da cultura (ETc) foi introduzido por Doorenbos \& Pruitt (1977), caracterizando-a como sendo a evapotranspiração de uma cultura agronômica, livre de doenças, desenvolvendo-se em uma área cultivada de um ou mais hectares, sob condições otimizadas de solo, incluindo água e fertilidade.

Jensen et al. (1990) afirmam que na prática a estimativa da evapotranspiração de uma cultura específica (ETc) envolve o cálculo da evapotranspiração potencial (ETp) de uma cultura de referência, aplicando-se posteriormente coeficientes de cultivo $(\mathrm{Kc})$. Outras formas de se estimativa da evapotranspiração potencial (ETp) são possíveis, por exemplo, o uso da evaporação de uma superficie livre de água. Contudo, a taxa de evaporação de tanques varia com o tamanho do tanque e com as condições de contorno. O mesmo autor sugere que a ETo pode ser definida como "a taxa com que a água, se disponível, é removida da superficie do solo e das plantas, de uma cultura específica, arbitrariamente chamada de cultura de referência". A ETo é normalmente expressa como taxa de calor latente por unidade de área ou lâmina de água evaporada. A ETo é equivalente a evapotranspiração potencial com uma especificação adicional de que ela representa a evapotranspiração de uma cultura com umidade do solo ideal e cobertura total da área. 
Encontra-se na literatura duas definições mais comuns para a evapotranspiração de referência: uma relacionada com a cultura de referência grama (ETo) e outra com a cultura de referência alfafa (ETr). Doorenbos \& Pruitt (1977) definiram ETo como sendo a evapotranspiração que ocorre em uma extensa superficie de grama, com porte de 8 a $15 \mathrm{~cm}$, em crescimento ativo, cobrindo totalmente o solo e sem restrição de água. Por sua vez, Jensen (1973) definiu ETr como sendo a evapotranspiração que se verifica em uma cultura de alfafa, com 30 a $50 \mathrm{~cm}$ de altura e bordadura mínima de $100 \mathrm{~m}$, cultivada sem deficiência hídrica. Embora se reconheça que a alfafa possua características aerodinâmicas mais representativas das culturas agronômicas do que a grama, esta última é mais utilizada pelo simples fato de a grande maioria das estações agrometeorológicas serem gramadas (Jensen, 1973; Smith 1991). Outro ponto favorável à grama é que ela se adapta mais facilmente à diferentes condições climáticas do que a alfafa. Beard ${ }^{3}$, citado por Jensen et al. (1990), discutiu os efeitos da estrutura e da densidade do dossel de diversas variedades de grama, e da orientação foliar nas taxas de evapotranspiração, encontrando baixas taxas de evapotranspiração relacionadas com uma relação baixa de folha/brotos, orientação foliar horizontal, altura de corte baixa e um "stand" uniforme e denso. Estes efeitos estão relacionados com uma redução da área foliar (incremento da resistência do dossel) e com uma baixa rugosidade da superficie (incremento da resistência aerodinâmica).

Smith (1991) propôs que se adote uma definição padronizada para a evapotranspiração de referência, com vistas, principalmente, à utilização do modelo de Penman-Monteith. A evapotranspiração de referência seria aquela que ocorre em uma cultura hipotética, apresentando as seguintes características: altura de $12 \mathrm{~cm}$, resistência do dossel de 69 s.m m $^{-1}$ e coeficiente de reflexão (albedo) de $23 \%$.

A evapotranspiração de referência pode ser determinada de diferentes maneiras. De acordo com Burman et al. (1983) ela pode ser estimada a partir de medidas diretas ou

\footnotetext{
${ }^{3}$ BEARD, J. R. An assessement of water use by turfgrass. IN GBEAULT, V. A.; COCKERHAM, S. T. Turfgrass water conservation. Davis, Univ. of Calif. , Div. of Agric. and Nat. Resour., 1985, 155p.
} 
de informações climáticas. No primeiro grupo, entre outros, estão incluídos os diferentes tipos de lisímetros e o balanço de água no solo; enquanto no segundo, estão enquadrados os modelos teóricos e empíricos, como os de Penman (1948), Thornthwaite (1948), Blaney \& Criddle (1950), Jensen \& Haise (1963), Priestley \& Taylor (1972), Hargreaves (1977) e evaporímetros como o tanque “"“Classe A"”, dentre outros.

O método de Penman é amplamente utilizado porque facilita o entendimento dos processos físicos da evaporação de superficies naturais e, também, porque se utiliza informações meteorológicas coletadas em um único nível acima da superficie evaporante (Thom \& Oliver, 1977; Brutsaert, 1982; Luchiari Jr., 1988). Porém, verifica-se que o método original de Penman não é um caso geral para estimativa da evapotranspiração, mas sim um caso muito particular aplicado a superficies de água livre, como um lago ou tanque "Classe A", ou a superficies molhadas como uma vegetação após uma chuva ou irrigação por aspersão (Monteith, 1965; Thom, 1975; Monteith, 1980; Brutsaert, 1982; Monteith, 1985; Oke, 1992).

Muitos pesquisadores procuraram superar esta falta de generalidade do método de Penman, cabendo a Monteith (1965) a obtenção de uma equação geral válida para qualquer tipo de vegetação, sob qualquer condição de estresse hídrico. Ele generalizou o método de Penman através de uma analogia com a lei de $\mathrm{Ohm}$ para os circuitos elétricos, introduzindo no termo aerodinâmico a resistência à transferência do vapor de água do dossel.

O método de Penman-Monteith, apesar de ter uma formulação teórica rigorosamente fisica, de fácil entendimento e requerer a utilização de informações climatológicas padronizadas, tem sua aplicação prática limitada pelas dificuldades de se obter valores confiáveis e representativos para a resistência do dossel (Norman \& Campbell, 1983; Monteith, 1985; Luchiari Jr., 1988; Hatfield, 1988; Villa Nova \& Reichardt, 1989; Luchiari Jr. \& Riha, 1991 e Oke, 1992). 
As dificuldades para se estimar a resistência do dossel decorrem do fato de ser uma função composta de muitos fatores ambientais e biológicos, tais como radiação solar, déficit de saturação de vapor de água, disponibilidade de água no solo, índice de área foliar (IAF), idade da planta, entre outros, cujos efeitos individuais não são fáceis de serem isolados (Monteith, 1985).

A resistência do dossel pode ser estimada a partir de medidas diretas da resistência estomática média, com porômetros de difusão, e do índice de área foliar da planta, obtido por amostragem. No entanto, esta é uma tarefa árdua e trabalhosa.

Os valores conhecidos de $r_{c}$ para as diferentes culturas estão ao redor de $20 \mathrm{~s} . \mathrm{m}^{-1}$ para solos com a umidade próximo à capacidade de campo, aumentando à medida que a umidade do solo diminui. Este fato evidencia a necessidade de pesquisar a variação desta resistência em função da disponibilidade de água no solo. Esta parametrização de $r_{c}$, para condições ótimas e de restrição de água no solo, permitirá que se estime a evapotranspiração real a partir do modelo Penman-Monteith (Hatfield, 1988).

Monteith (1985) sugere que se adote $\mathrm{rc}=50 \mathrm{~s} \cdot \mathrm{m}^{-1}$ para a determinação da evapotranspiração potencial das plantas cultivadas. Este valor concorda com os valores apresentados por Oke (1992), listados a seguir: grama, 70s $\mathrm{m}^{-1}$; culturas agrícolas, $50 \mathrm{~s} \cdot \mathrm{m}^{-1}$; florestas, 80 a $150 \mathrm{~s} \mathrm{~m}^{-1}$.

Peres (1994), trabalhando com dados de três localidades do Estado de São Paulo, verificou que o método de Penman desenvolvido segundo a parametrização da FAO, estimou a evapotranspiração de referência de forma consistente e que a resistência de dossel que melhor representa as condições de evapotranspiração potencial situa-se na faixa de 60 a 80 s.m. ${ }^{-1}$.

Maggiotto (1996), estimando os valores de resistência de dossel como resíduo de utilização do modelo de Penman-Montheith, a partir das variáveis meteorológicas médias 
no período de 24 horas e utilizando a ETo medida em um lisímetro de pesagem, encontrou valores que variaram de 53 a $256 \mathrm{sm}^{-1}$, com valor médio de $144 \mathrm{sm}^{-1}$.

Campeche (1997) verificou que os valores de resistência do dossel estimados a partir da termometria ao infra-vermelho foram bastante próximos do valor parametrizado pela FAO. Utilizando um período maior de dados durante a estação seca, Pereira (1998) observou nesse período um valor de resistência do dossel igual a $40 \mathrm{~s} \cdot \mathrm{m}^{-1}$.

Apesar desta dificuldade, SMITH (1991) propõe que, a princípio, a evapotranspiração de referência seja estimada pelo modelo de Penman-Monteith, considerado superior aos demais na estimativa da evapotranspiração potencial, para uma ampla diversidade de climas e locais.

\subsection{Balanço de energia}

O balanço de energia das superficies vegetadas permite dimensionar as trocas de massas e energia no sistema solo-planta-atmosfera, através do estudo da partição do saldo de radiação nos diversos processos que ocorrem na cultura em função dos estádios de desenvolvimento e das condições de umidade do solo e na atmosfera.

Os métodos de estimativa da evapotranspiração que se baseiam no balanço de energia são os mais consistentes. A metodologia é sempre a seguinte: uma vez determinado o balanço de radiação sobre a superficie, procura-se avaliar qual a fração do balanço que é utilizada no processo evaporação/evapotranspiração. Como a evaporação é basicamente um processo de transferência de energia, é possível, então, a aplicação do princípio da conservação de energia para estimar a transferência de água para a atmosfera em forma de vapor, (Berlato e Molion, 1981). 
Para que se possa estudar um sistema, sob qualquer ponto de vista, é necessário caracterizá-lo. No caso, o sistema a ser estudado é um volume de controle localizado numa área cultivada de altura $\mathbf{Z}$, comprimento $\mathbf{X}$ e largura $\mathbf{Y}$, contendo em seu interior ar atmosférico e certo número de plantas, sendo denominado de meio a parte externa que interage com esse sistema (Figura 1). Nestas circunstâncias, as principais trocas de energia entre sistema e o meio, bem como, os armazenamentos decorrentes são: $R$ n (fluxo líquido de energia radiante); $\mathrm{H}$ (fluxo convectivo de calor sensível); LE (fluxo convectivo de calor latente); $\mathrm{G}$ (fluxo de calor para o solo - condução); $\mathrm{L}_{1}$ e $\mathrm{L}_{2}$ (fluxos de calor latente devido ao fluxo de massa); $\mathrm{C}_{1}$ e $\mathrm{C}_{2}$ (fluxos de calor sensível devido ao fluxo de massa); $\Delta \mathrm{V}$ (armazenamento de calor latente pelo sistema), $\Delta \mathrm{S}$ (armazenamento de calor sensível pelo sistema) e, $\Delta \mathrm{F}$ (energia fixada em sínteses).

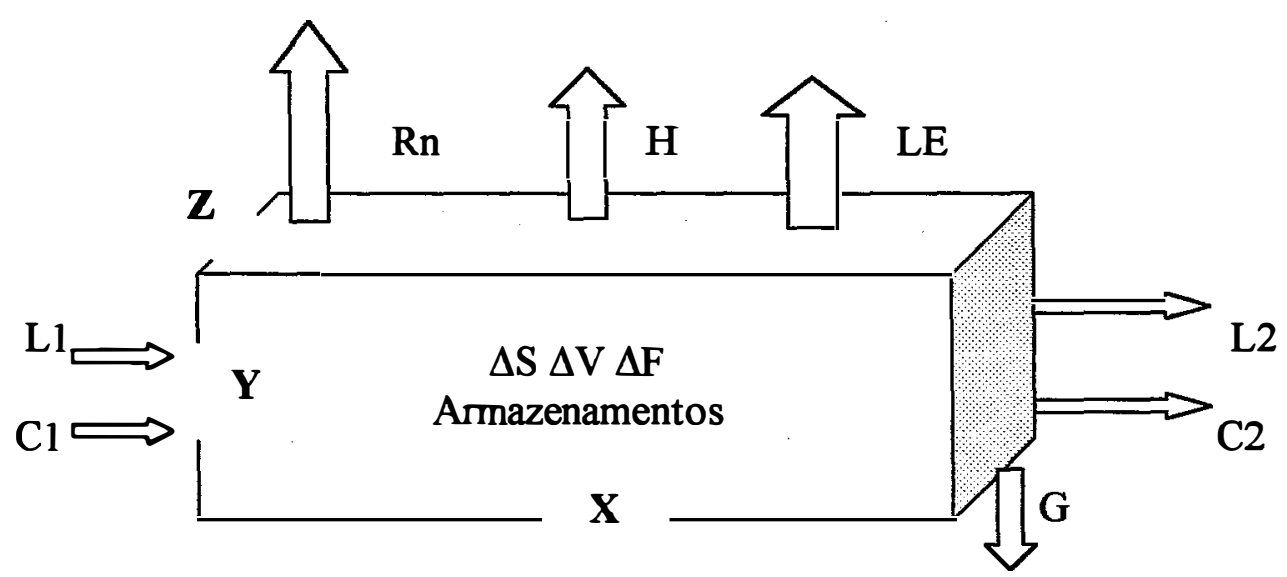

Figura 1 - Principais fluxos de energia no volume de controle

São desprezados os fluxos de calor sensível por condução pelas paredes laterais (exceto a do solo) devido à baixa condutividade térmica do ar e as pequenas diferenças de temperatura. Num instante qualquer, a soma algébrica dos fluxos de armazenamento deve ser nula, de tal modo que:

$\mathrm{G}+\mathrm{R}_{\mathrm{n}}+\mathrm{H}+\mathrm{LE}+\Delta \mathrm{S}+\Delta \mathrm{V}+\left(\mathrm{L}_{1}+\mathrm{L}_{2}\right)+\left(\mathrm{C}_{1}+\mathrm{C}_{2}\right)+\Delta \mathrm{F}=0$

Definindo-se alguns dos termos do balanço em função de variáveis do sistema e meio, tem-se : 
$\Delta S=\int_{0}^{2} C p \cdot \rho \cdot \frac{\delta T}{\delta t} \cdot d z+\int_{0}^{2} C c \cdot \rho c \cdot \frac{\delta T}{\delta t} \cdot d z$

$\Delta V=\int_{0}^{\infty} \frac{\lambda E}{R t} \cdot \frac{\delta e}{\delta t} \cdot . d z$

$\left(\overline{L_{1}+L_{2}}\right)=\int_{0}^{-} \frac{\lambda E}{R} \cdot \nabla_{H} \cdot \frac{U e}{T} \cdot d z$

$\left(\overline{C_{1}+C_{2}}\right)=\int_{0}^{T} C p \cdot \nabla_{H} \cdot(\rho U T) \cdot d z$

Segundo Villa Nova, (1973), com base nestas considerações as seguintes afirmações são válidas:

a) Os termos $\Delta \mathrm{S}$ (armazenamento de calor sensível pelo ar e vegetais do sistema) e $\Delta \mathbf{V}$ (armazenamento de calor latente) são desprezíveis em relação a $\mathrm{Rn}$, de acordo com verificações feitas por Rider \& Robinson (1951);

b) Os fluxos $\left(\mathrm{L}_{1}+\mathrm{L}_{2}\right)$ e $\left(\mathrm{C}_{1}+\mathrm{C}_{2}\right)$ são também desprezíveis, fazendo-se as medidas a baixa altura (z pequeno) e dentro de uma área tampão suficientemente grande para que os gradientes horizontais de temperatura e umidade sejam praticamente absorvidos;

c) A fração de energia em sínteses biológicas $(\Delta \mathrm{F})$ quase nunca ultrapassa a $3 \%$ de $R_{n}$, podendo também ser desprezada.

Em face das considerações anteriores, a equação(1),tornar-se-á:

$R n=\lambda E+H+G+A$

em que "A" se refere a divergência horizontal de calor (advecção). 
Desprezando o termo A (referente à divergência horizontal), a equação (6), assume a seguinte forma.

$R n=\lambda E+H+G$

Bowen (1926) definiu a relação entre os fluxos $\mathrm{H}$ e $\lambda \mathrm{E}$ (quociente entre o fluxo de calor sensível e o fluxo de calor latente) que foi denominada razão de Bowen $(\beta)$ e tem sido largamente utilizada em estudos de fluxo de calor, evapotranspiração e também para estimar a resistência imposta pelo sistema planta-atmosfera ao fluxo de vapor d'água (Fontana et al. 1991). Assim,

$\beta=\frac{H}{\lambda E}$

que aplicada à equação (7) resulta em:

$R n=\lambda E(1+\beta)+G$

Considerando médias de longo prazo, o termo de condução de calor para o sub meio $(G)$ deve tender a zero $(\bar{G} \cong 0)$. Dessa forma, denotando por uma barra médias de longo prazo tem-se:

$\overline{R n}=\overline{\lambda E}(1+\beta)$

Desde que os fluxos verticais de calor sensível, latente e de momento sejam do tipo convectivo forçado (fluxo turbulento em condições de atmosfera neutra), os mesmos podem ser calculados em função dos gradientes médios de temperatura $(T)$, umidade específica (q) e velocidade de vento (U), de acordo com as seguintes equações:

$\mathrm{H}=-\rho \cdot \mathrm{Cp} \cdot \mathrm{Kh} \cdot \frac{\delta \bar{T}}{\delta z}$ 
$\lambda \mathrm{E}=-\rho \cdot \lambda \cdot \mathrm{Kw} \cdot \frac{\delta \bar{q}}{\delta z}$

$\tau=\rho . \mathrm{Km} \cdot \frac{\delta \bar{U}}{\delta z}$

em que, $\rho$-é a densidade do ar seco $\left(1,26 \mathrm{~kg} \cdot \mathrm{m}^{-3}\right), \lambda$ é o calor latente de evaporação $(2,45$ MJ.kg $\left.{ }^{-1}\right), K_{h}$ é o coeficiente de transferência turbulenta de calor sensível, $K_{W}$ é o coeficiente de transferência turbulenta de calor latente e $\mathrm{K}_{\mathrm{m}}$ é o coeficiente de transferência turbulenta do momento.

Consoante com as determinações feitas por Pasquill (1949), Swinbank (1951) e Rider (1954), citados por Villa Nova (1973), em condições de atmosfera próxima da neutralidade os valores dos coeficientes de transferência turbulenta de calor sensível $\left(\mathrm{K}_{\mathrm{h}}\right)$, latente $\left(\mathrm{K}_{\mathrm{W}}\right)$, e momento $\left(\mathrm{K}_{\mathrm{m}}\right)$, tendem para a igualdade, ou seja:

$\mathrm{K}_{\mathrm{m}}=\mathrm{K}_{\mathrm{W}}=\mathrm{K}_{\mathrm{h}}$

Considerando-se a definição de umidade específica $(q)$ como sendo igual a :

$\mathrm{q}=0,622 \cdot \frac{e}{P}$

E substituindo-se (11), (12) e (15) em (8), obtém-se a expressão de $\beta$ usada por Webb (1965), conforme Villa Nova (1972):

$$
\beta=\frac{1}{\left(\frac{G+\gamma}{\gamma}\right) \cdot\left(\frac{\Delta T U}{\Delta T}\right)-1}
$$

Substituindo-se também (8) em (7), obtêm-se: 
$\lambda \mathrm{E}=-\frac{R n+G}{1+\beta} \quad$ para $\beta \neq-1$

O conjunto de equações (16), (17) e (8) constituí a formulação do método de balanço de energia e permite calcular os fluxos turbulentos de calor latente $(\lambda \mathrm{E}) \mathrm{e}$ sensivel $(H)$ sobre uma superficie natural, desde que se conheçam: $R_{n}=$ radiação líquida medida ao nível $Z_{2} ; G=$ fluxo de calor no solo medido na superficie; $\Delta T U=T_{2}-T_{1}$ (diferença de leituras de termômetros úmidos colocados aos níveis $Z_{2}$ e $Z_{1}$ ); $\Delta T=T_{2}-T_{1}$ (diferença de leituras de termômetros secos colocados aos níveis $Z_{2}$ e $Z_{1}$ ); $s=$ tangente à curva de tensão de saturação de vapor sobre água no ponto de temperatura média úmida (MTU), i.e., o valor médio de $\mathrm{TU}_{2}+\mathrm{TU}_{1} ; \gamma=\mathrm{A} . \mathrm{P}=$ constante psicrométrica reduzida, ou seja, produto da constante psicrométrica $(\mathrm{A})$ pela pressão atmosférica local $(\mathrm{P})$.

A condição hídrica da superficie evaporante afeta diretamente o valor de $\beta$, interferindo assim na partição da radiação líquida $(\mathrm{Rn})$. Desta maneira, quando a superficie apresentar restrição hídrica o valor de $\beta$ será elevado devido a maior parte de RN ser utilizada no aquecimento do ar $(\mathrm{H})$. Caso a umidade da superficie seja elevada uma parte maior de $\mathrm{Rn}$ será destinada para a evaporação de água (LE), e, conseqüentemente, o valor de $\beta$ será reduzido. Tanto $\mathrm{LE}$ como $\mathrm{H}$ são negativos quando fluem da superficie para o ar, e positivos no sentido contrário. Logo, para uma superficie evaporante, o sinal de $\beta$ depende apenas do sinal de $\mathrm{H}$. Se $\mathrm{H}$ for positivo, $\beta$ será negativo; se $\mathrm{H}$ for negativo, $\beta$ será positivo. Portanto, $\beta$ negativo significa que está havendo transporte de calor sensível do ar mais quente para a superficie mais fria, condição de adveç̧ão ou de inversão térmica; nesse caso, LE pode até suplantar Rn pois $\mathrm{H}$ representa um adicional de energia disponível à superficie evaporante (Pereira et al. 1997).

Muitos autores têm utilizado a razão de Bowen para a resolução do balanço de energia. Atualmente denomina-se método do balanço de energia todo aquele que utiliza a razão de Bowen para o cálculo dos fluxos de calor sensível e latente. 
O método da razão de Bowen tornou-se muito conhecido para a estimativa da evapotranspiração (ET) através do trabalho realizado por Tanner (1960) que apresentou uma boa concordância entre o método da razão de Bowen e lisímetros.

A aplicabilidade e a precisão do método da razão de Bowen têm sido avaliadas em muitos trabalhos (Tanner, 1960; Fritschen, 1965; Fuchs \& Tanner, 1970; Villa Nova, 1973; Blad \& Rosenberg, 1974) com uma precisão típica de aproximadamente $10 \%$ (Sinclar et al., 1975).

A maior dificuldade associada ao método da razão de Bowen é a instrumentação, que deve detectar as diferenças de temperatura e pressão de vapor numa mesma altura, supondo-se que existe uma similaridade do transporte turbulento do calor e do vapor de água, e conseqüentemente, as fontes de calor e vapor de água estão uniformemente distribuídas sobre a superficie. Um procedimento comum para minimizar erros é modificar a posição dos sensores durante o desenvolvimento das culturas, intercambiando a posição dos sensores durante o tempo de amostragem.

Trabalhando com o método do balanço de energia em Piracicaba - SP, Leite (1978) obteve valores de evapotranspiração do feijoeiro de 0,003 a $0,836 \mathrm{~mm} \cdot \mathrm{h}^{-1}$, superiores à estimada pelo método de Penman sobre superficie gramada.

Bergamaschi et al. (1988) avaliaram os componentes do balanço de energia em cultura do feijoeiro submetida a condições variáveis de disponibilidade hídrica no solo e de demanda evaporativa da atmosfera. De acordo com os autores a quantidade de energia destinada aos processos de evapotranspiração foi maior em níveis mais elevados de índice de área foliar, de disponibilidade hídrica e de demanda evaporativa da atmosfera. $\mathrm{O}$ inverso ocorreu com relação à energia utilizada no aquecimento do ar e do solo.

Fontana et al. (1991), utilizando o método do balanço de energia para cultura da soja no Rio Grande do Sul, verificaram que o fluxo de calor latente de evaporação representou a maior porção do saldo de radiação, sendo $95 \%$ na parcela irrigada e $78 \%$ na 
parcela irrigada. O fluxo de calor no solo representou a menor porção do saldo de radiação, sendo $2 \%$ e $7 \%$ na parcela irrigada e não irrigada, respectivamente.

De acordo com Doorenbos e Pruitt (1977), o termo de maior importância nos estudos de evapotranspiração para manejo da irrigação é a radiação líquida.

A radiação líquida muitas vezes não é medida diretamente. A grande dificuldade em se utilizar sensores para medida direta da radiação líquida é o custo do sensor e sua rápida deterioração em relação a outros equipamentos meteorológicos. Outro problema é que para utilizar a radiação líquida para estimativa da evapotranspiração de referência (ETo), o sensor deve ser instalado sobre uma superficie gramada e irrigada, sendo muito difícil encontrar e manter uma área padrão irrigada.

Usando dados de radiação medida com piranômetro Eppley, Ometo (1968) determinou para Piracicaba - SP, as relações entre radiação solar global, radiação líquida e insolação para duas épocas.

Escobedo \& Souza (1997), analisaram os componentes do balanço de radiação em relação ao índice de área foliar (IAF) em várias fases fenológicas da cultura do feijãovagem (Phaseolus vulgaris L.), em Botucatu, SP, sob duas diferentes condições: a cultura em condições normais de campo e em casa de vegetação com cobertura de polietileno.

De acordo com Llasat \& Snyder (1998), o sensor de radiação líquida é talvez o mais delicado de todos os sensores utilizados em estações meteorológicas. Apesar de serem calibrados anualmente e sofrerem manutenções periódicas é comum a ocorrência de diferenças acima de $10 \%$ entre valores calibrados e mensurados em campo $\left(60 \mathrm{~W} / \mathrm{m}^{2}\right.$ $\mathrm{em} \mathrm{Rn}=600 \mathrm{~W} / \mathrm{m}^{2}$ ).

Comparando dados meteorológicos obtidos concomitantemente por uma estação meteorológica convencional e uma automática, Sentelhas (1998) desenvolveu, testou e validou vários modelos de regressão linear de estimativa da radiação líquida a partir de 
diferentes elementos meteorológicos. Para dados da estação meteorológica automática, essa estimativa pode ser obtida a partir da radiação global $(\mathrm{Qg})$, com a relação $\mathrm{Rn}=$ $0,574 \operatorname{Qg}\left(r^{2}=0,9073\right)$. 


\section{BALANÇO DE ENERGIA NA CULTURA DE FEIJÃo UTILIZANDO UM SISTEMA DE RAZÃO DE BOWEN}

\subsection{Resumo}

Muitos pesquisadores têm notado a necessidade de métodos simples e acurados de estimativa da evapotranspiração das culturas (ETc). Embora muitas equações de estimativa da evapotranspiração tenham sido propostas, a grande disponibilidade de dados climáticos tem gerado interesse em equações capazes de estimar a evapotranspiração diária baseadas em variáveis ambientais coletadas em um curto intervalo de tempo. As equações de estimativa em tempo real necessitam de uma série de dados mais intensa e contínua, entretanto as estações meteorológicas automáticas disponíveis no mercado são capazes de suprir a necessidade de dados de entrada para estas equações. $O$ método do balanço de energia tem sido amplamente utilizado para quantificar as principais trocas de energia entre sistema solo planta e o meio. Os componentes do balanço de energia foram estudados para a cultura do feijão (Phaseolus vulgaris L.) sob condições variáveis de disponibilidade de água no solo e demanda evaporativa da atmosfera durante as diferentes fases de desenvolvimento da cultura em um experimento de campo desenvolvido em Piracicaba - SP, à latitude $22^{\circ} 43^{\prime} 33^{\prime \prime}$ sul, longitude $47^{\circ} 38^{\prime} 0^{\prime \prime}$ oeste e altitude de $576 \mathrm{~m}$. O sistema automático mediu a evapotranspiração em intervalos de 20 minutos, durante o período de luz utilizando as seguintes leituras: Radiação líquida (Rn); fluxo de calor no solo $(G)$ e gradiente psicromérico $(\Delta \mathrm{e})$ utilizando termopares de cobre Constantan. $\mathrm{O}$ fluxo de calor latente (LE) e o fluxo de calor sensível $(\mathrm{H})$ foram calculados de acordo com as medidas mencionadas anteriormente e com uso da razão de Bowen. A evapotranspiração da 
cultura estimada pelo sistema de razão de Bowen foi comparada com os valores medidos pelo lisímetro de pesagem. Os resultados permitiram analisar as relações entre os fluxos de calor latente (LE), sensível (H) e a radiação líquida (Rn).

\subsection{Summary}

Many researchers have noted the need for accurate and relatively simple methods to estimate crop evapotranspiration (ET). Although many models for predicting ET have been proposed. The amount of weather data available is generating interest in models that are able to estimate daily ET by integrating environmental measurements collected at short-time intervals. Although short-time interval models require more intensive data sets, automated weather stations that are capable of supplying the necessary data inputs are commercially available. The energy balance - Bowen ratio method - has been largely applied for quantifying physical properties fluxes in the atmospheric boundary layer. The energy balance components were studied for dry beans (Phaseolus vulgaris L.) crop under different conditions of soil water availability and atmospheric evaporative demand, during different growing crop stages in a field experiment station at Piracicaba - SP, Brazil, at $22^{\circ} 43^{\prime} 33^{\prime \prime}$ south latitude, $47^{\circ} 38^{\prime} 0^{\prime \prime}$ west longitude, and $576 \mathrm{~m}$ altitude. The equipment to measure the evapotranspiration at intervals of 20 minutes, during the daytime using the following readings: net radiation ( $R n)$, soil heat flux $(G)$ and psychrometric gradient profiles measured with copper-constantan thermocouples. The latent heat flux (LE) and sensible heat flux $(\mathrm{H})$ in the atmosphere were calculated based on the above measurements and on Bowen ratio. The ET estimated by Bowen ratio method was compared with the ET measured by a weighing lysimeter. The results allowed analyzing the $\mathrm{LE}, \mathrm{H}$ and $\mathrm{Rn}$ relations.

\subsection{Introdução}

O estudo de métodos práticos de medida da evapotranspiração tem o objetivo de entender os processos micrometeorológicos nas áreas irrigadas. $O$ manejo da irrigação é 
essencial para a otimização dos recursos hídricos. Sistemas de irrigação apresentam elevado custo e sua viabilidade econômica é função do incremento da produção pela da irrigação. Inicialmente, para conseguir este objetivo é necessário estimar o consumo de água da cultura em campo. Estimativas micrometeorológicas do fluxo de vapor de água na atmosfera podem fornecer valores representativos da evapotranspiração.

Estimativas acuradas da evapotranspiração (ET) sempre são requeridas em estudos de campo, em que lisímetros podem não ser disponíveis para se obter medidas diretas. A medida da evapotranspiração utilizando um dispositivo lisimétrico poder ser realizado somente para uma única cultura, a menos que exista vários lisímetros instalados em um dado local. A utilização de métodos micrometeorológicos possibilita uma comparação entre as medidas de evapotranspiração de diferentes culturas no campo. Os equipamentos utilizados nos métodos micrometeorológicos são facilmente instalados e possuem uma maior mobilidade em relação aos dispositivos lisimétricos. $\mathrm{O}$ método do Balanço de energia, devido a sua simplicidade e confiabilidade, é muito utilizado. Este método pode também ser utilizado em campo como uma medida padrão para calibrar modelos de estimativa da evapotranspiração baseados na resistência da cultura e no fluxo de massa (Prueger et al. 1997).

O método da razão de Bowen (Bowen, 1926) tem se tornado padrão para medir os fluxos de calor latente e sensível de acordo com o balanço de energia. A validade deste método foi verificada em vários trabalhos (Tanner, 1960; Villa Nova, 1973; Sinclar et al., 1975; Bergamaschi et al., 1988). Limitações do método da razão de Bowen geralmente ocorrem próximo ao nascer e ao por do sol, devido aos pequenos gradientes de temperatura $(\mathrm{T})$ e pressão de vapor (e) que resultam em valores da razão de Bowen ( $\beta$ ) próximos de -1 . Limitações podem também ocorrer com culturas com cobertura vegetal desuniforme e em condições de advecção.

A grande diferença nos processos de transferência de energia que ocorrem durante o dia e a noite, é devido à disponibilidade de energia e a instabilidade da 
atmosfera. Alguns autores consideram confiáveis somente os gradientes medidos durante o período de luz, excluindo os dados perdidos correspondentes aos períodos chuvosos ou que possuam erros de medida (Ashktorab et al. 1989; Heilman and Brittin, 1989; Cellier et al., 1996;Unland et al. 1996).

A estimativa dos fluxos verticais pela razão de Bowen é baseada na resolução do balanço de energia. A razão de Bowen é a razão entre o fluxo de calor sensível e o fluxo de calor latente e pode ser expresso com sendo proporcional a razão entre o gradiente de temperatura e o gradiente de pressão de vapor entre dois níveis. De acordo com o balanço de radiação, a radiação líquida é composta de fluxo de calor latente (LE), fluxo de calor sensível $(\mathrm{H})$, e fluxo de calor no solo (G). Os principais requerimentos do método da razão de Bowen são que os gradientes de temperatura e psicrométrico sejam medidos dentro da camada limite que deverá estar em equilíbrio com a superfície. $\mathrm{O}$ principal objetivo deste trabalho foi quantificar os fluxos de calor latente (LE), calor sensível $(\mathrm{H})$, pelo do método do Balanço de energia em diferentes fases de desenvolvimento de uma cultura de feijão em condições variáveis de demanda evaporativa da atmosfera, em Piracicaba - SP e analisar a performance de funcionamento de um sistema automático de razão de Bowen em relação a um lisímetro de pesagem.

\subsection{Material e Métodos}

O experimento foi conduzido em condições de campo durante o período de 13 de agosto a 12 de novembro de 1998 na área experimental do Departamento de Engenharia Rural da Escola Superior de Agricultura "Luiz de Queiroz". Em Piracicaba, SP,

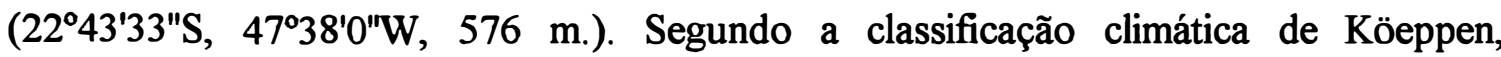
Piracicaba possui clima do tipo Cwa, ou seja, subtropical úmido, com estiagem no inverno, com temperatura média no mês mais frio inferior a $18^{\circ} \mathrm{C}$ e no mês mais quente superior a $22{ }^{\circ} \mathrm{C}$. A temperatura média anual é de $21,1^{\circ} \mathrm{C}$ e a precipitação média anual é de aproximadamente $1250 \mathrm{~mm}$. 
Uma parcela experimental de 3,5 ha irrigada por pivô central, cultivada com a variedade IAC carioca Pyatã (ciclo de 98 a 105 dias), foi semeada em 13 de Agosto de 1998 , com espaçamento entre linhas de $0,60 \mathrm{~m}$, na densidade de 12 plantas $/ \mathrm{m}^{2}$. A cultura do feijão recebeu adubação (base e cobertura) conforme análise do solo e o controle fitosanitário foi realizado de acordo com as recomendações técnicas para a cultura. Durante o período de desenvolvimento foram feitas observações fenológicas e medidas do índice de área foliar (IAF), num intervalo médio de sete dias. A cultura foi muito bem suprida de água com $o$ intuito de manter as condições ideais de evapotranspiração potencial.

Durante o transcorrer do experimento foram realizadas medidas micrometeorológicas para fornecer valores médios em intervalos de tempo de 20 minutos sobre a cultura para alguns dias do ciclo de desenvolvimento da cultura $(17 / 09 ; 22 / 09$; 01/10; 19/10 e 21/10. As medidas do sistema de razão de Bowen começaram após a emergência e foram realizadas até a época de colheita. As determinações da temperatura do ar $\left({ }^{\circ} \mathrm{C}\right)$ e umidade absoluta $\left(\mathrm{g} / \mathrm{cm}^{3}\right)$ foram feitas nos níveis 0,25 e $1,0 \mathrm{~m}$ acima da superficie vegetal. A radiação líquida $\left(\mathrm{W} / \mathrm{m}^{2}\right)$ e o fluxo de calor no solo $\left(\mathrm{W} / \mathrm{m}^{2}\right)$ também foram mensurados. Estes dados foram obtidos utilizando um sistema automático de razão de Bowen fabricado pela Campbell Scientific.

A medida direta da evapotranspiração da cultura (ETc) foi feita utilizando lisímetro de pesagem. $\mathrm{Na}$ área cultivada com a cultura do feijão foi instalado um lisímetro com as seguintes dimensões: $0,70 \mathrm{~m}$ de profundidade, $1,50 \mathrm{~m}$ de comprimento e $1,30 \mathrm{~m}$ de largura. Detalhes da construção deste equipamento podem ser observado em Silva (1999).

Inicialmente, foram realizadas calibrações no lisímetro de pesagem e dos sensores meteorológicos. Posteriormente, os dados foram examinados com intuito de evitar possiveis erros devido a problemas de instrumentação. A evapotranspiração da cultura foi 
computada na escala horária durante os períodos nos quais a radiação líquida $(\mathrm{Rn})$ foi maior que zero $\mathrm{W} \cdot \mathrm{m}^{-2}$, sendo então totalizada para valores diários.

A partir das medições de radiação líquida $(\mathrm{Rn})$, fluxo de calor no solo $(G)$ e diferenças de temperatura e pressão de vapor entre dois níveis, o balanço de energia pode ser apresentado como:

$\mathrm{Rn}-\mathrm{G}-\mathrm{H}-\mathrm{LE}=0$

em que $\mathrm{Rn}$ é a radiação líquida; $\mathrm{G}$ é o fluxo de calor no solo; $\mathrm{H}$ é o fluxo de calor sensível; e LE é o fluxo de calor latente

O método da razão de Bowen estima os fluxos de calor sensível e latente baseado na resolução da equação do balanço de energia, considerando a razão de Bowen ( $\beta$ = $\mathrm{H} / \mathrm{LE})$

$$
\mathrm{LE}=-\frac{(\mathrm{Rn}+\mathrm{G})}{(1+\beta)}
$$

Durante um período de $20 \mathrm{~min}$, assumindo a similaridade dos coeficientes de transporte turbulento (Verma et al. 1978) e mensurando a os gradientes de temperatura $\mathrm{e}$ pressão de vapor entre dois níveis ajustados a cobertura vegetal, a razão de Bowen ( $\beta$ ) foi calculada a partir da equação

$$
\beta=\gamma \frac{\Delta T}{\Delta e}
$$

em que $\gamma$ é a constante psicrométrica; $\Delta \mathrm{T}$ é a diferença de temperatura entre dois níveis sobre a superfície; $\Delta \mathrm{e}$ é a diferença de pressão de vapor para os mesmos dois níveis. $\mathrm{O}$ fluxo de calor sensível foi determinado utilizando a equação (1). Os valores de evapotranspiração foram estimados usando as equações (2) e (3). 
A convenção usada para os sinais dos fluxos de energia é Rn positivo quando flui do solo para a superficie e $\mathrm{G}$ positivo quando é conduzido da superficie para o interior do solo. Os fluxos de calor sensível e latente são negativos quando fluem da superficie para o ar, e positivos no sentido contrário. Para um gradiente de temperatura $(\Delta \mathrm{T} / \Delta \mathrm{z})<0$, o fluxo de calor sensível é positivo, e para um gradiente de pressão $(\Delta e / \Delta z)<0$, o fluxo de calor latente é positivo.

\subsection{Resultados e Discussão}

Os valores do índice de área foliar (IAF) são apresentados na Figura 1. O período com maior incremento do IAF ocorreu 35 dias após o plantio (17 / setembro), atingindose um valor máximo em torno de 2,74 a 2,83, para, logo em seguida, decrescer devido a senescência da cultura.
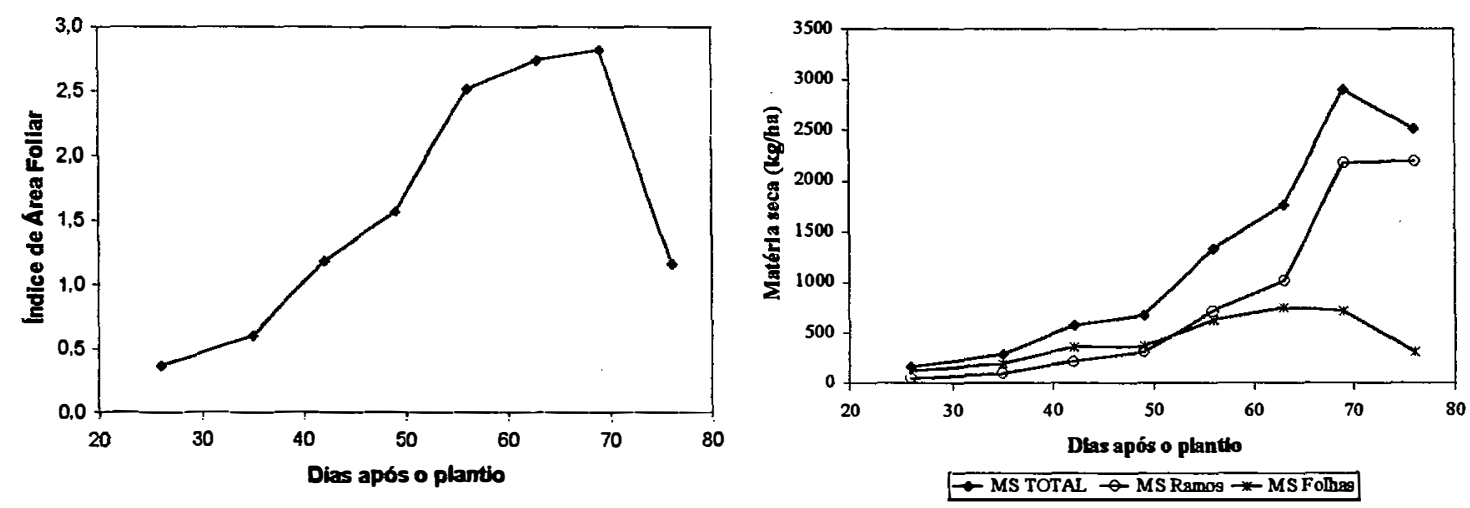

Figura 1 - İndice de área foliar (IAF), MS total, MS ramos e MS folhas $\mathrm{kg} / \mathrm{ha}$ da cultura de feijão em relação ao período do experimento. Piracicaba, SP.

Observa-se na Figura 1 que a massa seca das folhas até o início do mês de outubro correspondia a metade da massa seca total. A partir deste período ocorreu uma inversão devido o aumento da massa seca dos ramos, este último no final do período correspondia a quase $90 \%$. da massa seca total. 
Os componentes do balanço de energia, em diferentes fases de desenvolvimento da cultura do feijão, para cinco dias típicos de demanda evaporativa da atmosfera encontram-se na Tabela 1. Pode-se observar que no dia 22 de setembro ocorreu advecção de calor sensível, resultando em um fluxo de calor sensível maior do que a radiação líquida $(\mathrm{Rn})$ disponível $(\mathrm{LE} / \mathrm{Rn}<-1)$.

Tabela - 1 Componentes do Balanço de energia (MJ.m ${ }^{-2}$.Período de Luz $\left.{ }^{-1}\right)$ medidas sobre uma cultura de feijão em diferentes dias. Piracicaba, SP.

\begin{tabular}{cccccccccc}
\hline & Período & Rn & G & H & LE & LE/Rn & H/Rn & G/Rn & LAI \\
\hline 17/ Set /98 & $07-17 h$ & 11,75 & 1,00 & $-4,46$ & $-6,29$ & $-0,535$ & $-0,380$ & 0,053 & 0,6 \\
01/ Out /98 & $07-17 \mathrm{~h}$ & 9,25 & 0,30 & $-3,32$ & $-5,62$ & $-0,608$ & $-0,359$ & 0,022 & 1,57 \\
19/ Out /98 & $07-18 \mathrm{~h}$ & 14,47 & 0,44 & $-1,76$ & $-12,27$ & $-0,848$ & $-0,121$ & 0,019 & 2,74 \\
21/ Out /98 & $06-18 \mathrm{~h}$ & 13,81 & 0,72 & $-1,95$ & $-11,14$ & $-0,807$ & $-0,141$ & 0,030 & 2,82 \\
22/ Set /98 & $07-18 \mathrm{~h}$ & 9,71 & 0,21 & 1,15 & $-10,65$ & $-1,097$ & 0,119 & 0,019 & 1,18 \\
\hline
\end{tabular}

Pode-se observar que ocorreu uma variação na quantidade de energia disponível, compreendida entre 14,47 MJ.m. ${ }^{-2}$. Período de $\mathrm{Luz}^{-1}$ e 9,25 MJ.m ${ }^{-2}$. Período de Luz ${ }^{-1}$, juntamente com as variações de desenvolvimento da cultura, cujo IAF variou entre $0,6 \mathrm{e}$ 2,82 .

As condições de disponibilidade hídrica no solo foram mantidas sem déficit para evitar restrições na taxa de evapotranspiração.

As Figuras 3A, 3C, 4A e 4C apresentam os componentes da partição do balanço de energia sobre uma cultura de feijão, bem como suas relações com a radiação líquida para os dias 17/09, 01/10,19/10 e 21/10, respectivamente. 

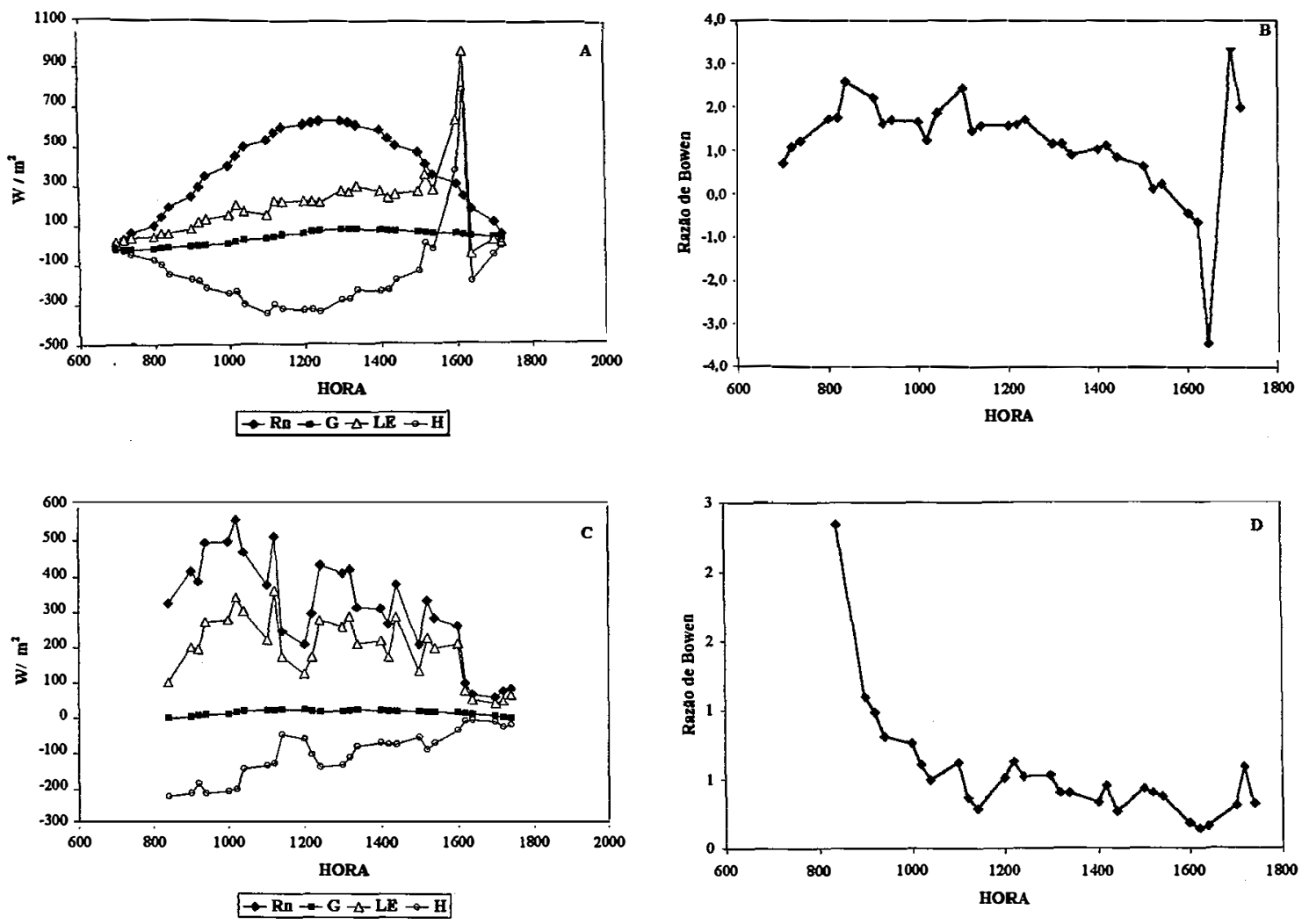

Figura 3. Componentes do Balanço de energia $\left(\mathrm{W} / \mathrm{m}^{2}\right)$ sobre a cultura do feijão para o dia 17/09 (A) e dia 01/10 (C). Razão de Bowen para o 17/09 (B) e dia 01/10 (D).

As Figuras 3 e 4 apresentam diferenças nos componentes em função da fase de desenvolvimento da cultura (IAF - Figura 1). No primeiro período (Figuras 3A e 3C) caracterizado pelo menor desenvolvimento das plantas (IAF $<1,6$ ), a maior quantidade da radiação líquida foi empregada como calor sensivel, $37 \%$ da $\mathrm{Rn}$ foi utilizada para aquecimento do ar e 3,7\% no aquecimento do solo. No período (Figuras 4A e 4C) cujo IAF foi maior que 2,7, nota-se que a energia disponível foi fracionada em $13 \%$ para fluxo de calor sensível e $2,45 \%$ para o fluxo de calor no solo (Tabela 1 ). 

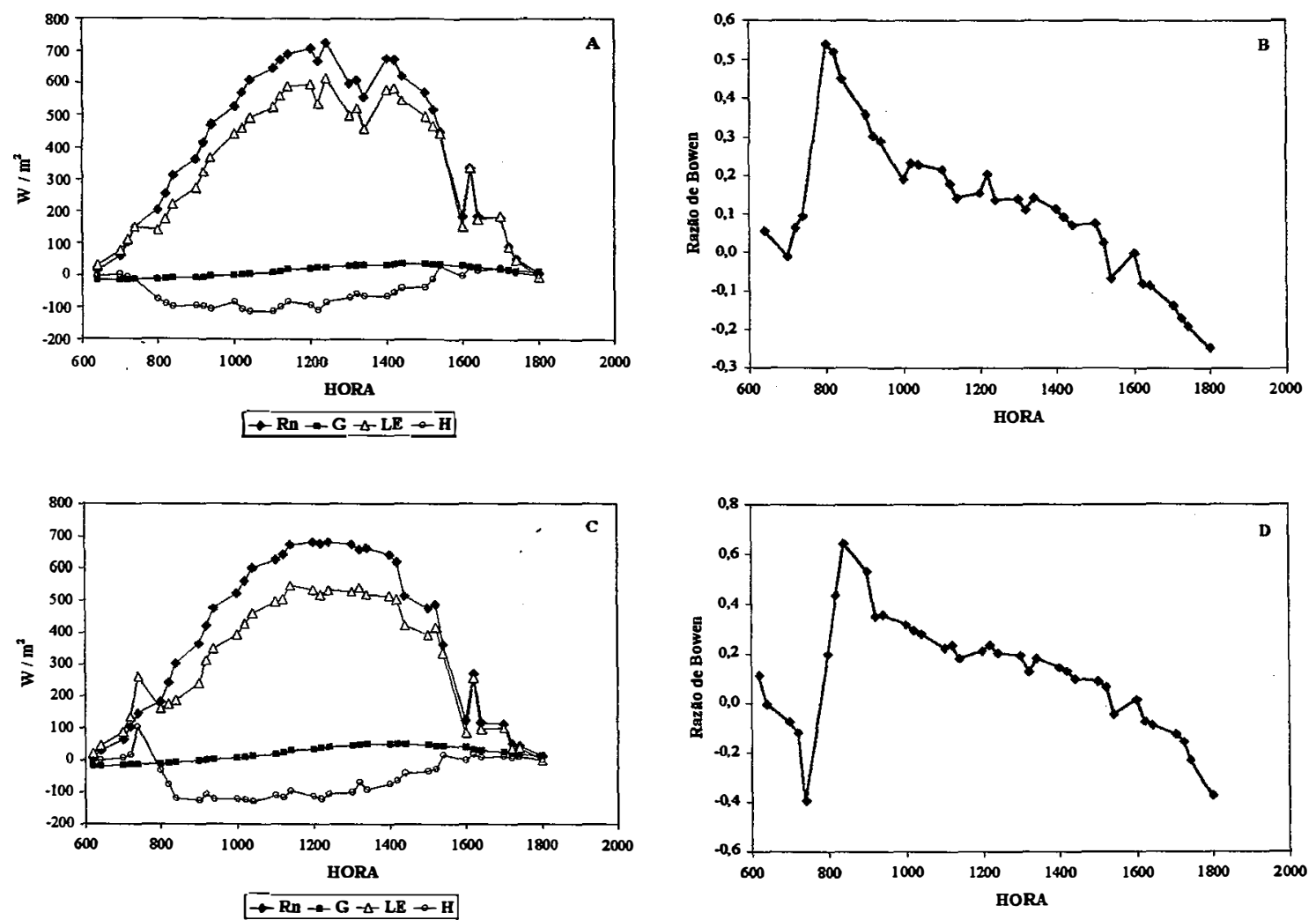

Figura 4. Componentes do Balanço de energia $\left(\mathrm{W} / \mathrm{m}^{2}\right)$ sobre a cultura do feijão para o dia 19/10 (A) e dia 21/10 (C). Razão de Bowen para o 19/10 (B) e dia 21/10 (D).

Na Figuras (3B-3D; 4B-4D) são representadas as variações da razão de Bowen ( $\beta$ ) calculadas. Os valores de $\beta$ decresceram durante o dia, devido ao incremento da disponibilidade de energia para o fluxo de calor latente (LE). Na maior parte do período analisada a razão de Bowen foi positiva, apresentando valores superiores a unidade. Pelas Figuras 4B e 4D constata-se que a razão de Bowen foi positiva durante a maior parte do dia, porém suas magnitudes foram inferiores às obtidas nos dias 19/07 e 01/10 (Figuras 3B e 3D), não sendo verificado valores superiores à unidade. Portanto, em nenhum instante o fluxo de calor sensível foi superior ao fluxo de calor latente de evaporação. Os valores negativos de $\beta$ indicam a transferência de energia do meio para $o$ sistema. Verificou-se que elevados valores de $\beta$ ocorreram, a razão disto não está totalmente explicado. Variações da razão de Bowen podem ser explicados pelas flutuações na 
radiação líquida, resistência da cultura (rc) e diferença de pressão de vapor entre a folha e ar atmosférico.

Na Tabela 1 constata-se que dentre os componentes do balanço de energia, 0 fluxo de calor no solo sempre se apresentou como o menor valor em termos absolutos. Proporcionalmente, a radiação líquida $(\mathrm{Rn})$ o fluxo de calor no solo foi $5,3 \%, 2,2 \%$, $1,9 \%$ e $3,0 \%$ para os dias $17 / 09 ; 01 / 10 ; 19 / 10$ e $21 / 10$, respectivamente.

Pode-se observar que no dia 22/09 a advecção do calor sensível $(+\mathrm{H})$ foi cerca de $11 \%$ da radiação líquida $(\mathrm{Rn})$, resultando em um fluxo de calor latente (LE) superior a energia disponível (Tabela 1). Verifica-se na Figura 5 que, a razão de Bowen foi predominantemente negativa. Houve transferência de energia do meio para o sistema, implicando em ocorrência de fluxos de calor sensível positivos. Este processo ocorreu no período em que a cultura não cobria totalmente o solo e parte da energia não utilizada originária da superficie do solo foi transportada para as plantas.
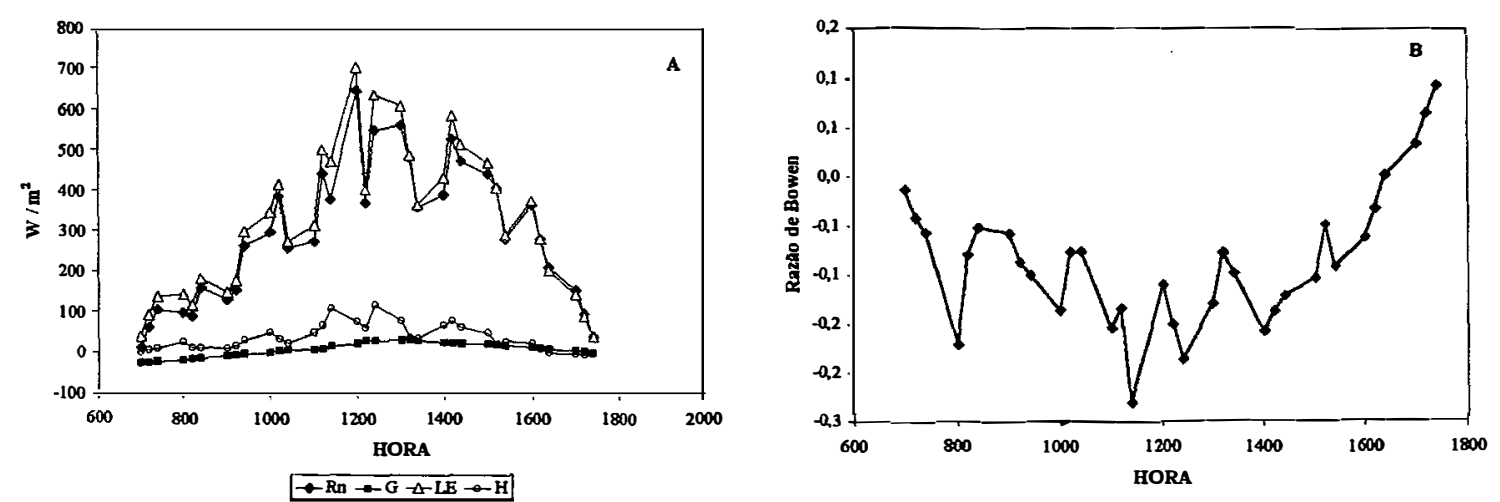

Figura 5. Componentes do Balanço de energia $\left(\mathrm{W} / \mathrm{m}^{2}\right)$ sobre a cultura do feijão para o dia 22/09 (A) e Razão de Bowen para o 22/09 (B).

Os valores da evapotranspiração obtida pelo método do Balanço de energia foram comparados com os valores medidos em lisímetro de pesagem. Para o total do período estudado, obteve-se os seguintes valores para evapotranspiração cultura do feijão: ET Lisímetro $=151,36 \mathrm{~mm}$ e ET Balanço de energia $=130,82 \mathrm{~mm}$. A evapotranspiração obtida pelos dois métodos apresentaram uma performance similar em relação a resposta 
as condições ambientais durante o período de estudo (Figura 6). A comparação entre as estimativas do método do Balanço de energia e lisímetro de pesagem mostrou que o lisímetro de pesagem apresentou valores diários de evapotranspiração superiores ao método do Balanço de energia, e embora a concordância entre as duas séries de dados tenha sido boa, o método do Balanço de energia subestimou a evapotranspiração medida pelo lisímetro de pesagem. Isto pode ser evidenciado pela equação de regressão entre os dois métodos, cujo coeficiente angular foi de 0,94, coeficiente linear igual 0,9463 e o coeficiente de determinação $\left(\mathrm{r}^{2}\right)$ de 0,86 . $\mathrm{O}$ incremento da evapotranspiração medida pelo lisímetro pode ser devido a condições de umidade do solo dentro do lisímetro próximo da saturação.
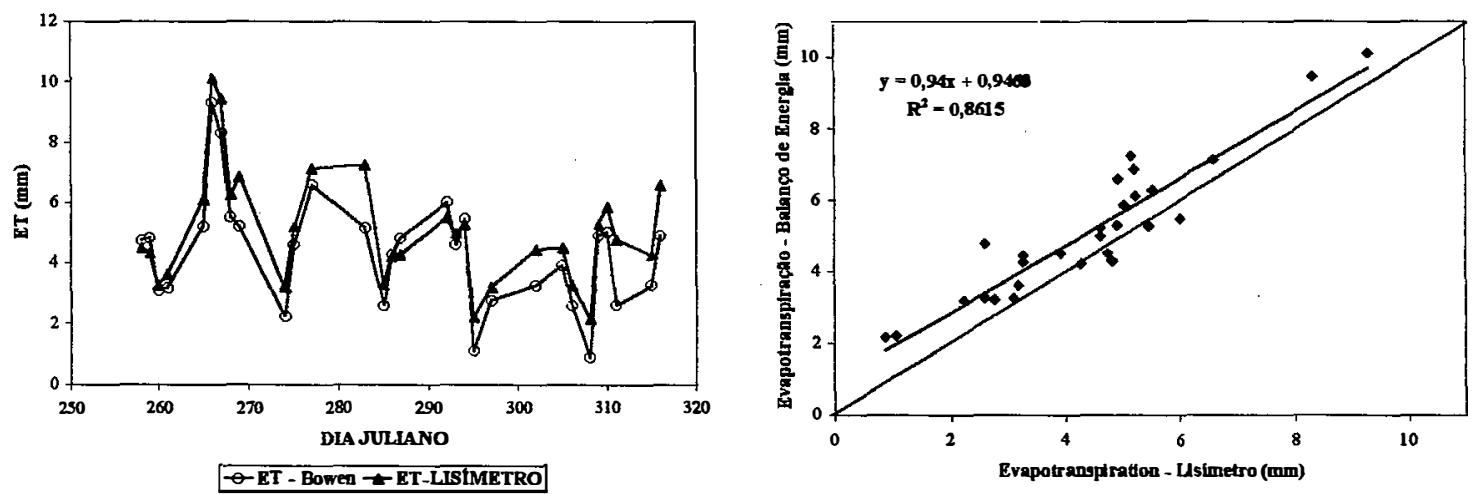

Figure 6. Valores de Evapotranspiração, em mm, estimados pelo método do Balanço de energia e lisímetro de pesagem para a cultura do feijão, durante o período do experimento, Piracicaba, SP.

Com o objetivo de comparar as estimativas do fluxo de calor latente (LE) realizadas pelo método do Balanço de energia e lisímetro de pesagem, pares de dados foram plotados na Figura 7. Os dados foram restritos ao horário de luz, considerando o período de 17/09 a 12/11. O fluxo de calor latente estimado pelo lisímetro de pesagem foi calculado multiplicando a evapotranspiração medida pelo calor latente de vaporização ( $\lambda$ ). Ocorreu uma excelente concordância na maior parte do período entre as estimativas dos dois métodos (Figura $7 \mathrm{~A}-\mathrm{C}$ ). Algumas diferenças refletem as limitações no procedimento utilizado para obter as leituras do lisímetro, principalmente em condições 
de fortes ventos. Entretanto, as diferenças entre os valores medidos e calculados na escala horária devem ser consideradas como reais. A análise de regressão linear entre o fluxo de calor latente ( $\mathrm{LE}$ ) estimado pelo método do Balanço de energia e lisímetro de pesagem produziu um coeficiente angular de 0,77 e o intercepto de $9,86 \mathrm{~W} \cdot \mathrm{m}^{-2}$, com $\mathrm{r}^{2}$ igual a 0,90 para o dia 17/09 e, um coeficiente angular de 0,95, coeficiente linear de 7,72 $\mathrm{W} / \mathrm{m}^{2}, \operatorname{com} \mathrm{r}^{2}=0,97$ para o dia $21 / 10$. Os resultados encontrados estão dentro do erro médio reportado por Sinclar et al (1975). Blad \& Rosenberg (1974) apresentaram regressões lineares entre o calor latente (LE) estimado pelo método do Balanço de energia e lisímetro de pesagem com coeficientes angulares variando de 0,7 a 0,93.
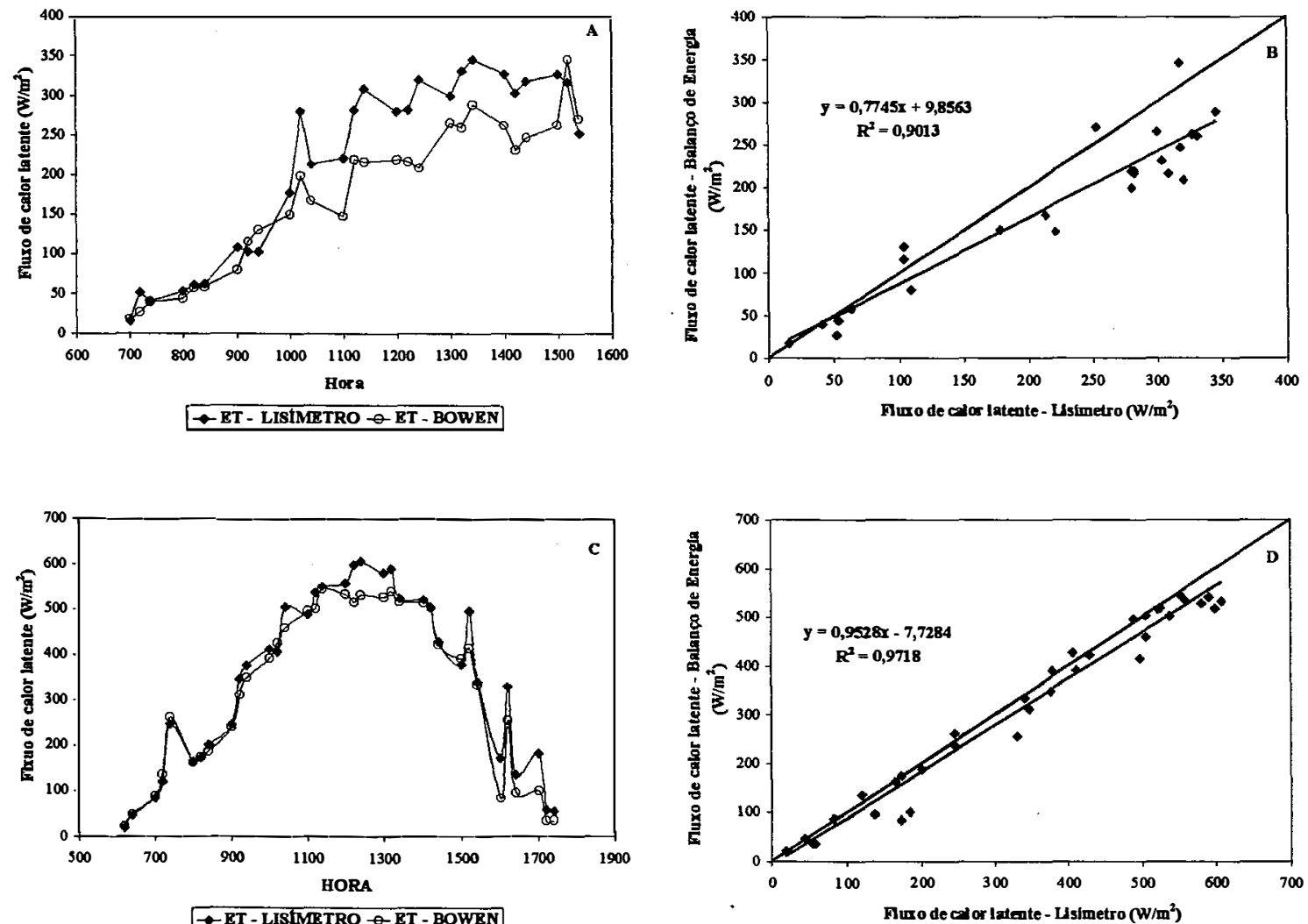

Figura 7 - Comparação entre o fluxo de calor latente calculado pelo método do Balanço de energia e o lisímetro de pesagem ns dias 17/09 (A - B) e 21/10 (C - D), Piracicaba, SP. 


\subsection{Conclusões}

A quantidade de energia utilizada no fluxo de calor latente de evaporação (evapotranspiração) foi influenciada pelo índice de área foliar e pela demanda evaporativa da atmosfera. A menor porção da radiação líquida foi utilizada no aquecimento do solo, sendo influenciado pela cobertura vegetal.

Para o período estudado, obteve-se os seguintes valores para evapotranspiração da cultura do feijão: ET Lisímetro $=151,36 \mathrm{~mm}$ e ET Balanço de energia $=130,82 \mathrm{~mm}$. sendo que o método do Balanço de energia subestimou a evapotranspiração com relação ao lisímetro de pesagem em cerca de $16 \%$.

Considerando a variação normal das condições ambientais, a concordância e a consistência das duas técnicas (Método do Balanço de energia e Lisímetro de pesagem) considerou-se como adequada a determinação da evapotranspiração durante o período do experimento. Os resultados deste trabalho permitem indicar a utilização do sistema de razão de Bowen para obtenção de estimativas da evapotranspiração representativas da cultura de feijão similares as medidas realizadas em lisímetro de pesagem. 


\section{RELAÇÃo ENTRE A RADIAÇÃo SOLAR E RADIAÇÃO LÍQUIDA SOBRE SUPERFÍCIES VEGETADAS}

\subsection{Resumo}

A maioria dos métodos meteorológicos utilizados para estimar a evapotranspiração de culturas requer informações a respeito do saldo de radiação. A radiação líquida ou saldo de radiação muitas vezes não é medida diretamente em razão do custo do sensor.Medidas da radiação líquida $(\mathrm{Rn})$ e Global $(\mathrm{Qg})$ foram feitas sobre uma superficie gramada e vegetada com a cultura de feijão em um experimento de campo desenvolvido em Piracicaba - SP, à latitude $22^{\circ} 43^{\prime} 33^{\prime \prime}$ sul, longitude $47^{\circ} 38^{\prime} 0^{\prime \prime}$ oeste e altitude de $576 \mathrm{~m}$. A radiação líquida disponível para superficie gramada foi inferior a energia disponível para a superficie cultivada com feijão. Regressões entre radiação líquida e a radiação global para as duas superficies vegetadas são apresentadas, $\mathrm{Rn}=$ $0,6069 \mathrm{Qg}\left(\mathrm{r}^{2}=0,899\right)$ para uma superficie gramada (Paspalum notatum flugge) e $\mathrm{Rn}=$ $0,6817 \mathrm{Qg}\left(r^{2}=0,9392\right)$ para uma superficie vegetada pela cultura do feijão (Phaseolus vulgaris L.).

\subsection{Summary}

The majority of the meteorological methods used to estimate the crop evapotranspiration require information about net radiation. Often net radiation isn't directly measured, because of the censor cost. Net $(\mathrm{Rn})$ and global $(\mathrm{Qg})$ radiation measures were taken on area vegetated with grass and on a crop bean areas in a field 
experiment station at Piracicaba - SP, Brazil, at $22^{\circ} 43^{\prime} 33^{\prime \prime}$ south latitude, $47^{\circ} 38^{\prime}$ 0 "'west longitude, and $576 \mathrm{~m}$ altitude.. The area vegetated with grass showed available net radiation inferior to the available energy obtained from the bean crop area.. Regressions between net and global radiation for both areas are showed : $\mathrm{Rn}=0,6069$ $\operatorname{Qg}\left(r^{2}=0,899\right)$ for the area vegetated with grass (Paspalum notatum flugge) and $\mathrm{Rn}=$ 0,6817 Qg $\left(r^{2}=0,9392\right)$ for the bean (Phaseolus vulgaris L.) crop area.

\subsection{Introdução}

A evapotranspiração pode ser obtida de diferentes formas: por meio de medidas diretas e de forma indireta a partir de fórmulas teóricas ou empíricas que utilizam dados do solo, dados meteorológicos $\mathrm{e}$ indicadores das plantas. $\mathrm{O}$ uso de métodos meteorológicos para determinar a evapotranspiração diária das culturas pode resultar em um uso mais eficiente da água de irrigação. A radiação líquida é o mais importante elemento usado em métodos meteorológicos combinados como Penman (1948) e no método do Balanço de energia (Tanner, 1960; Bergamaschi et al., 1988). Poucos dados de radiação líquida para superficies cultivadas são disponíveis. Entretanto, a radiação solar ou radiação global, é medida na maioria das estações meteorológicas e para a maioria das localidades. Assim sendo, torna-se interessante estimar a radiação líquida de maneira direta através dos dados de radiação global.

A radiação solar que penetra na atmosfera e atinge a superficie da terra depende principalmente da turbidez atmosférica, da cobertura de nuvem e da topografia. Essa energia, ao atravessar a atmosfera, tem parte refletida pelas nuvens, parte espalhada pelas moléculas e partículas do ar e parte absorvida pelo vapor de água, dióxido de carbono, ozônio e compostos nitrosos. A porção absorvida aumenta a temperatura do ar e por conseguinte aumenta a emissão de ondas longas para a superficie da terra e para o espaço. $O$ balanço de radiação representa, em última análise, as fontes e sumidouros de 
energia que afetam as condições meteorológicas e o clima do planeta (Souza \& Escobedo, 1997).

A radiação líquida muitas vezes não é medida diretamente. A grande dificuldade em se utilizar sensores para medida direta da radiação líquida é o custo do sensor e sua rápida deterioração em relação a outros equipamentos meteorológicos. Outro problema é que para utilizar a radiação líquida para estimativa da evapotranspiração de referência (ETo), o sensor deve ser instalado sobre uma superficie gramada e irrigada. Entretanto, é muito dificil encontrar e manter uma área padrão irrigada.

Usando dados de radiação medida com piranômetro Eppley, Ometo (1968) determinou para Piracicaba - SP, as relações entre radiação solar global, radiação líquida e insolação para duas épocas.

Souza \& Escobedo (1997), analisaram os componentes do balanço de radiação em relação ao índice de área foliar (IAF) em várias fases fenológicas da cultura do feijãovagem (Phaseolus vulgaris L.), em Botucatu - SP, sob duas diferentes condições: a cultura em condições normais de campo e em casa de vegetação com cobertura de polietileno.

De acordo com Llasat \& Snyder (1998), o sensor de radiação líquida é talvez o mais delicado de todos os sensores utilizados em estações meteorológicas. Apesar de serem calibrados anualmente e sofrerem manutenções periódicas, é comum a ocorrência de diferenças acima de $10 \%$ entre valores calibrados e mensurados em campo.

Comparando dados meteorológicos obtidos concomitantemente por uma estação meteorológica convencional e uma automática, Sentelhas (1998) desenvolveu, testou e validou vários modelos de regressão linear de estimativa da radiação líquida a partir de diferentes elementos meteorológicos. Para dados da estação meteorológica automática, essa estimativa pode ser obtida a partir da radiação global $(\mathrm{Qg})$, com a relação $\mathrm{Rn}=$ $0,574 \mathrm{Qg}\left(\mathrm{r}^{2}=0,9073\right)$. 
A evapotranspiração é largamente determinada pela energia radiante incidente, caracterizada pela radiação líquida. Tanner et al (1960) relata que a máxima evapotranspiração possível é aproximadamente igual a radiação líquida, exceto para dias com ventos fortes e de temperatura elevada, quando a advecção pode ser um fator importante, ou em dias com céu nublado e pouca radiação.

A radiação líquida é extremamente correlacionada com a radiação solar. Shaw (1956) relatou um coeficiente de correlação entre valores de radiação líquida e radiação global para o período de luz sobre superficie gramada de aproximadamente 0,98 em dias claros e 0,97 em dias encobertos. Esta correlação não pode ser aplicada para outras culturas. Decker (1959) afirmou que a radiação líquida aumenta com o incremento da altura da cobertura vegetal.

Estimativas reais de radiação líquida sobre superficies naturais como solo nu, gramado, culturas anuais e perenes são importantes para determinação da energia disponível para os processos de transferência de calor sensível e latente entre a superficie e a atmosfera.

A proposta deste trabalho é apresentar relações entre a radiação líquida e global medida sobre a cultura de feijão (Phaseolus vulgaris L.). Estas relações ilustram a qualidade da informação quando se estima a radiação líquida através da radiação global.

\subsection{Material e Métodos}

O experimento foi conduzido em condições de campo, na área experimental do Departamento de Engenharia Rural - ESALQ/USP, situada no município de Piracicaba SP, nas seguintes coordenadas geográficas: $22^{\circ} 42^{\prime} 30^{\prime \prime}$ de latitude Sul; $47^{\circ} 30^{\prime} 00^{\prime \prime}$ de longitude Oeste; e a 546 metros de altitude.

Segundo a classificação climática de Köeppen, Piracicaba possui clima do tipo Cwa, ou seja, subtropical úmido, com estiagem no inverno, com temperatura média no 
mês mais frio inferior a $18{ }^{\circ} \mathrm{C}$ e no mês mais quente superior a $22{ }^{\circ} \mathrm{C}$. A temperatura média anual é de $21,1^{\circ} \mathrm{C}$ e a precipitação média anual é de aproximadamente $1250 \mathrm{~mm}$.

Foram utilizados dados de radiação global e radiação líquida obtidos sobre uma superficie gramada (Paspalum notatum flugge) e outra cultivada com feijão (Phaseolus vulgaris L.). Os dados sobre a superficie gramada foram obtidos no Posto Agrometeorológico na área experimental do Departamento de Engenharia Rural. A cultura do feijão foi semeada na densidade de 12 plantas $/ \mathrm{m}^{2}$, no dia 13 de agosto de 1998, em uma área de 3,5 ha irrigada por pivô central. As duas áreas foram irrigadas freqüentemente, além disso as chuvas naturais serviram para manter as condições de umidade do solo ideais a evapotranspiração potencial.

Foram coletadas, num intervalo médio de 7 dias, amostras de plantas ( 4 repetições em 1 metro de linha) para determinação de massa seca total da parte aérea (MS), índice de área foliar (IAF) e altura da planta.

As medidas de radiação global e líquida foram coletadas por sistema de aquisição de dados (Datalogger 21X - Campbell Scientific), programado para fazer uma leitura a cada segundo e médias a cada 20 minutos. A radiação líquida $\left(\mathrm{MJ} / \mathrm{m}^{2} /\right.$ dia) foi medida a $1 \mathrm{~m}$ de altura da cobertura vegetal através de um saldo radiômetro (Modelo Q-7 net radiometer - REBS), para ambas as culturas. A radiação global ( $M J / \mathrm{m}^{2} / \mathrm{dia}$ ) foi medida a $3 \mathrm{~m}$ de altura da superficie gramada através de um piranômetro (modelo LI200X Licor). Os dados analisados foram obtidos durante o período de desenvolvimento da cultura do feijão. As mensurações foram realizadas para dias claros, sem ocorrência de chuva. $\mathrm{O}$ somatório de radiação para um dia é o equivalente a integração das leituras contínuas.

Os dados de radiação global e líquida, estimados e medidos, foram correlacionados utilizando planilha eletrônica, constituindo gráficos do tipo dispersão com os respectivos coeficientes de correlação e equação de regressão linear. A metodologia utilizada para comparação dos valores medidos e estimados de radiação 
líquida fundamentou-se no coeficiente de determinação $\left(r^{2}\right)$ e no erro padrão da estimativa (SEE), este último calculado pela expressão:

$$
\operatorname{SEE}=\left(\frac{\sum(y-\hat{y})^{2}}{n-1}\right)^{1 / 2}
$$

onde SEE é o erro padrão da estimativa ( $\left.\mathrm{MJ} / \mathrm{m}^{2} / \mathrm{dia}\right)$; y é a Rn medida; $\hat{y}$ é a $\mathrm{Rn}$ estimada pelo modelo de regressão e n o número de observações.

\subsection{Resultados e Discussão}

A altura da cultura de feijão durante o período de desenvolvimento encontra-se representada na Figura 1A. Pode-se notar que o período de maior taxa de crescimento se deu após o dia 260, correspondendo à fase de florescimento. Os valores do índice de área foliar (IAF) estão apresentados na Figura 1B e se comportaram de maneira similar aos valores da altura de planta. Assim como a altura da planta, houve um período de alta taxa de crescimento do IAF (após o dia 260), atingindo-se um valor máximo em torno de 2,74 a 2,83, para em seguida decrescer devido à senescência da cultura.
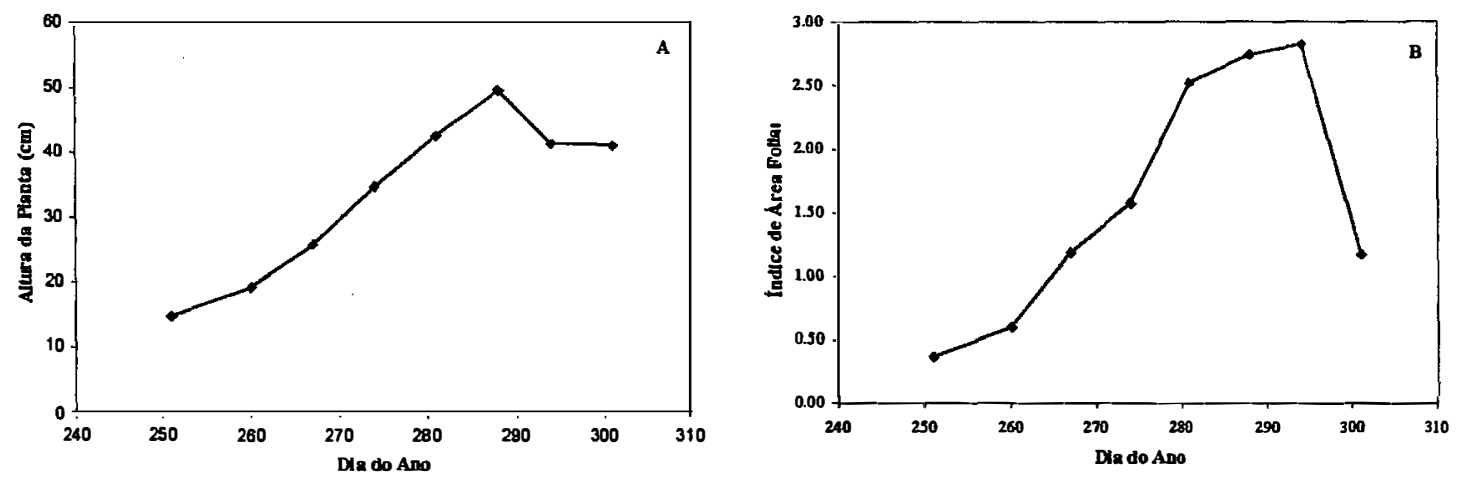

Figura 1 - (A) Altura de plantas de feijoeiro e (B) Índice de área foliar (IAF) em relação ao período do experimento.

As mensurações da radiação global e líquida foram realizadas durante o período de desenvolvimento (13/agosto - DJ 225 a 12 /novembro - DJ 316). A Figura 2 
apresenta as curvas de variação da radiação global e líquida para as superficies vegetadas por grama (Paspalum notatum flugge) e feijão (Phaseolus vulgaris L.) durante o seu período de desenvolvimento. As condições de cobertura do céu afetam significativamente todos os componentes do balanço de radiação, inclusive a radiação global $(\mathrm{Rg})$ e a radiação líquida $(\mathrm{Rn})$. Os dias com maior nebulosidade causaram uma diminuição em todos os componentes do balanço de radiação.

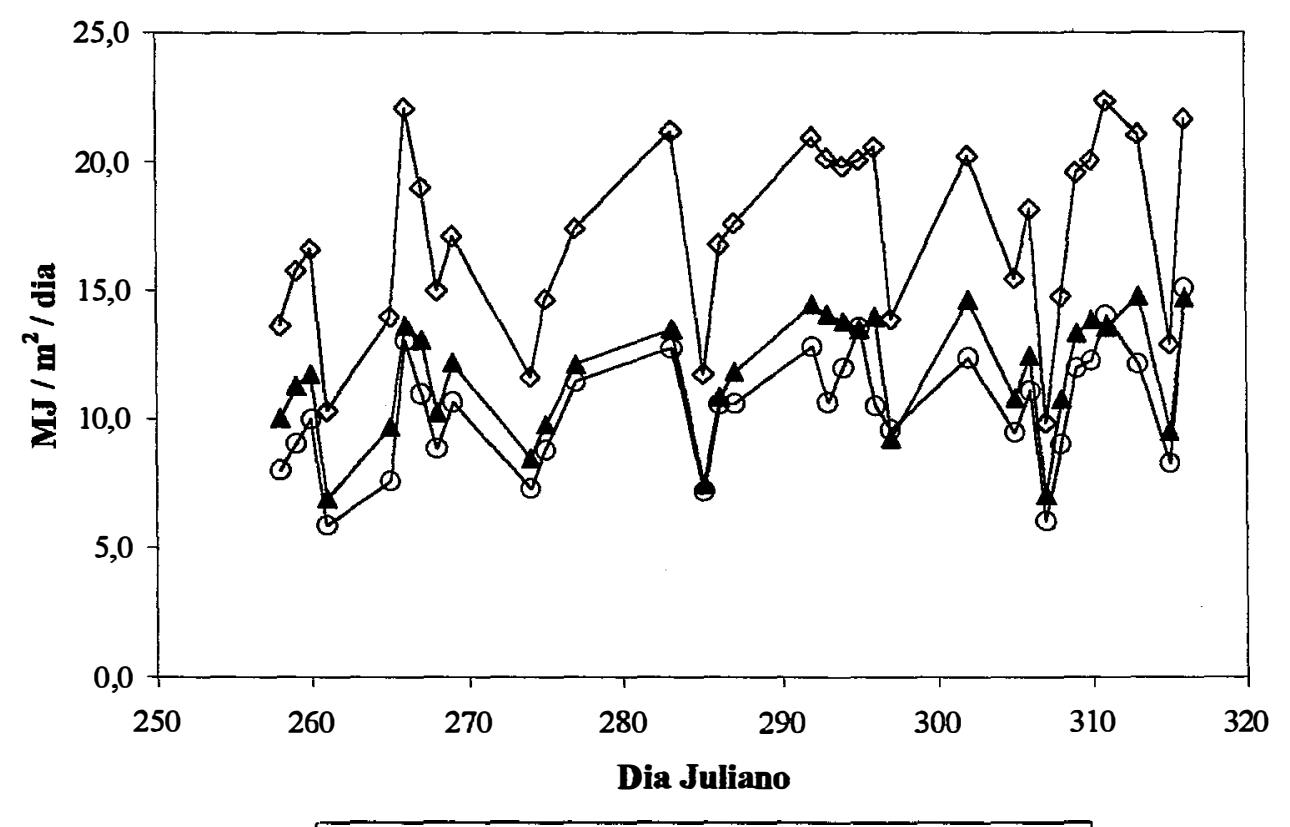

$\diamond$ Radiação Global $\theta-R n-G r a m a-t R n-F e i j a ̃ o$

Figura 2 - Radiação global $(\mathrm{Qg})$ e radiação líquida $(\mathrm{Rn})$ para uma superfície vegetada por grama (Paspalum notatum flugge ) e outra cultivada com feijão (Phaseolus vulgaris $\mathrm{L}$.).

De acordo com a Figura 2, observa-se que durante todo período de observação a radiação líquida sobre a grama foi menor do que a quantidade de energia disponível sobre a cultura do feijoeiro. Isto indica que a temperatura radioativa para a grama é menor em relação a temperatura da superficie vegetada com feijão. 
$\mathrm{Na}$ Tabela 1 estão apresentados os valores médios de radiação global $(\mathrm{Qg})$, radiação líquida (n), Índice de área foliar (IAF) e a razão entre Qg / Rn, em diferentes fases fenológicas da cultura do feijão. A média geral da razão Rn / Qg ficou em 69,30 \%, o que concorda com os resultados encontrados por Souza \& Escobedo (1997). Verificase, de maneira de maneira geral uma tendência de redução na razão de $\mathrm{Rn} / \mathrm{Qg}$ com o aumento da área foliar. Este aspecto fica melhor representado em termos médios por fase fenológica. De acordo com Souza \& Escobedo (1997), a diminuição da razão Rn / Qg com o aumento do índice de área foliar é conseqüência de uma maior perda por reflexão de ondas curtas podendo também ser favorecida por maior perda em ondas longas, graças a um maior aquecimento do dossel vegetativo.

Tabela 1 - Razão entre radiação global $(\mathrm{Qg})$ e radiação líquida $(\mathrm{Rn})$ para uma superficie cultivada com feijão (Phaseolus vulgaris L.) e índice de área foliar (IAF) em diferentes fases fenológicas. Piracicaba, SP.

\begin{tabular}{lcccc}
\hline FASE & $\begin{array}{c}\text { Dias após o } \\
\text { plantio }\end{array}$ & $\begin{array}{c}\mathrm{Rn} \\
\mathrm{MJ} \cdot \mathrm{m}^{2}\end{array}$ & $\begin{array}{c}\mathrm{Rn} / \mathrm{Qg} \\
\%\end{array}$ & IAF \\
\hline VEGETATIVA & $31-43$ & 98,79 & 71 & 1,18 \\
FLORESCIMENTO & $44-81$ & 191,00 & 68 & 2,74 \\
MATURAÇÃO & $82-92$ & 97,48 & 69 & 1,17 \\
\hline
\end{tabular}

Mensurações da radiação líquida sobre superficies vegetadas não são geralmente efetuadas. Na maioria dos casos essas medidas somente são realizadas durante um breve período de tempo e então relacionadas a estudos de balanço de energia. Regressões lineares entre o total de radiação global diário e o somatório da radiação líquida disponível, para as culturas são apresentadas na Figura 3. 

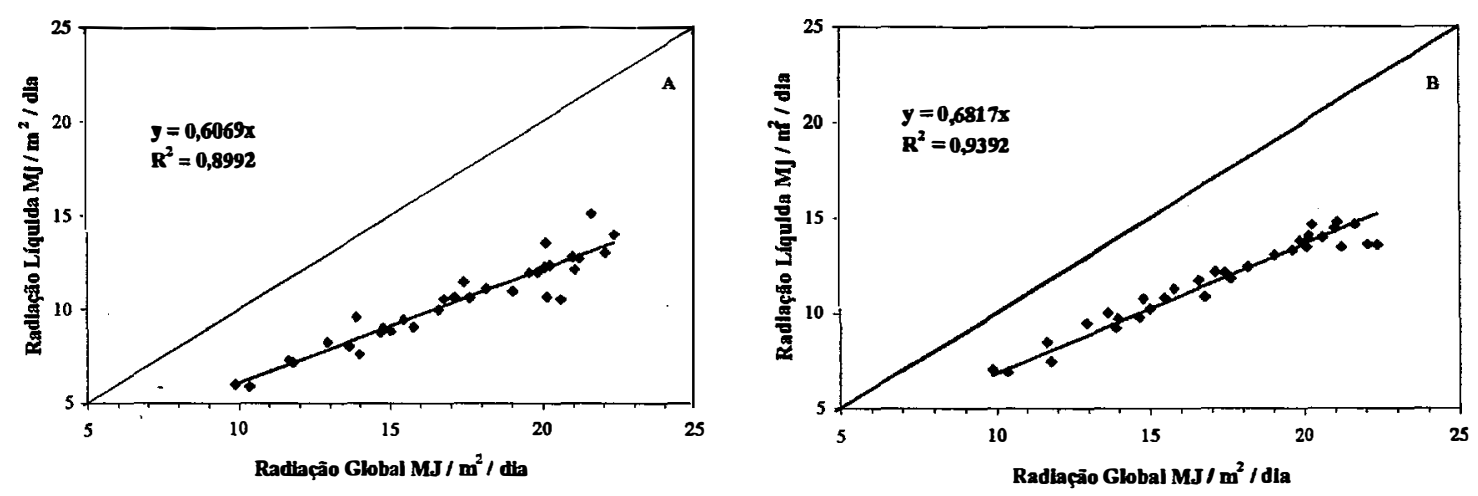

Figura 3 - Relação entre radiação líquida e radiação global para duas superficies vegetadas; Grama (A) e Feijão (B).

Na Tabela 2, são apresentadas as equações de regressão linear para estimativa da Rn em função da radiação global $(\mathrm{Qg})$ sobre superficie gramada e cultivada com feijão, tomando os valores como totais diários. Os elevados coeficientes de determinação, $r^{2}=$ 0,899 para superficie gramada e $r^{2}=0,939$ para superficie vegetada por feijão, indicam haver uma relação linear entre os dois tipos de radiação. $\mathrm{O}$ coeficiente angular da equação de regressão que foi forçada pela origem para melhor visualização da correlação foi de 0,6069 para grama e 0,6817 para cultura de feijão. De acordo com o esperado, observa-se que o coeficiente angular da correlação entre a radiação líquida e Global para grama é relativamente menor do que a apresentada para superficie vegetada por feijão. Os baixos valores de SEE, 0,27 MJ.m ${ }^{2} \cdot \mathrm{dia}^{-1}$ para a superficie gramada e 0,16 MJ.m $\mathrm{m}^{2} \cdot \mathrm{dia}^{-1}$ para a superficie cultivada com feijão confirma o bom ajuste das equações de estimativa.

Tabela 2 - Equações de regressão linear de estimativa da radiação líquida $(\mathrm{Rn})$, expressa em MJ.m².Período de Luz ${ }^{-1}$, em função da radiação global $(\mathrm{Qg})$ sobre superficie gramada e cultivada com feijão. Piracicaba - SP.

\begin{tabular}{lccc}
\hline Superficie & Equação de Regressão & $\mathrm{r}^{2}$ & SEE \\
\hline Gramada & $\mathrm{Rn}=0,6069 \cdot \mathrm{Qg}$ & 0,899 & 0,27 \\
Cultivada com feijão & $\mathrm{Rn}=0,6817 . \mathrm{Qg}$ & 0,939 & 0,16 \\
\hline
\end{tabular}


Sentelhas (1998), analisando um período maior de dados, encontrou que a estimativa da radiação líquida para superficies gramadas pode ser obtida a partir da radiação global $(\mathrm{Qg})$, com a relação $\mathrm{Rn}=0,574 \mathrm{Qg}\left(\mathrm{r}^{2}=0,9073\right)$.

$\mathrm{Na}$ ausência de dados de radiação líquida, essas equações de regressão podem prover boas estimativas para diferentes aplicações como, por exemplo, a estimativa de evapotranspiração das culturas utilizada em projetos de irrigação. Entretanto, o erro deve ser maior em uma escala diária, por exemplo para o manejo da irrigação. Portanto, outros fatores como a temperatura do ar e a pressão de vapor devem ser considerados em uma relação onde a radiação líquida é estimada a partir da radiação global.

\subsection{Conclusões}

A relação entre $Q g$ / Rn, nas diferentes fases fenológicas da cultura do feijão, variou (decresceu) com o aumento do índice de área foliar;

A radiação líquida, para efeito de elaboração de projetos de irrigação, pode ser estimada satisfatoriamente por regressão, em função da radiação global;

A radiação liquida da superficie gramada foi inferior à radiação líquida disponível para uma superficie vegetada pela cultura de feijão. 


\section{EVAPOTRANSPIRAÇÃO DO FEIJOEIRO (PHASEOLUS VULGARIS L.) E EVAPOTRANSPIRAÇÃO DE REFERÊNCIA DETERMINADAS PELOS MÉTODO DO BALANÇO DE ENERGIA E LISÍMETRO DE PESAGEM}

\subsection{Resumo}

Um estudo sobre o consumo de água do feijoeiro (Phaseolus vulgaris L.) foi realizado na área experimental do Departamento de Engenharia Rural - ESALQ/USP, situada no município de Piracicaba - SP. A irrigação foi aplicada por um pivô central com o intuito de manter o solo sem restrições hídricas. Os principais objetivos do estudo foram a mensuração da evapotranspiração da cultura e estimativas dos coeficientes de cultivo (Kc). A evapotranspiração da cultura do feijão na localidade de Piracicaba - SP foi de $4,36 \mathrm{~mm} / \mathrm{dia}$, ou $130,82 \mathrm{~mm}$ para o período de observação e $5,05 \mathrm{~mm} \cdot \mathrm{dia}^{-1}$ ou $151,36 \mathrm{~mm}$, respectivamente pelo método do Balanço de energia e lisímetro de pesagem. Os coeficientes de cultura $(\mathrm{Kc})$ foram 1,24 e 1,17 para a fase vegetativa, 0,76 e 0,73 para a fase de florescimento e formação de vagem, 0,62 e 0,67 para a fase de maturação e 0,85 e 0,84 para todo o ciclo, baseados no método do Balanço de energia e do lisímetro de pesagem, respectivamente. Não ocorreram diferenças significativas entre as estimativas de evapotranspiração e Kc (coeficientes de cultivo) realizadas para os dois métodos avaliados. 


\subsection{Summary}

The water consumption of the bean (Phaseolus vulgaris L.) crop was studied at the experimental area of the Rural Engineering Department - ESALQ/USP, in Piracicaba -SP. The irrigation was applied by center-pivot, in order to avoid any water deficit in the soil. The main objectives of the present study were the crop evapotranspiration measurement and the crop coefficient $(\mathrm{Kc})$ estimation. The bean crop evapotranspiration values obtained in the experiment, daily and during the whole period analyzed were, respectively, $4.36 \mathrm{~mm}$ and $130.82 \mathrm{~mm}$ by the Bowen ratio method and $5.05 \mathrm{~mm}$ and $151.36 \mathrm{~mm}$, by the weighing lysimeter. The crop coefficients $(\mathrm{Kc})$ values were 1.24 and 1.17 for the vegetative stage; 0.76 and 0.73 for the flowering and pods filling stages; 0.62 and 0.67 for the maturation stage and finally, 0.85 and 0.84 for the whole growth season, respectively, according to the Bowen ratio method and the weighing lysimeter. There weren't differences between evapotranspiration and Kc estimations, when both methods were evaluated.

\subsection{Introdução}

O excesso e o déficit de chuvas são os principais problemas que afetam a estabilidade da produção da cultura do feijoeiro. A sazonalidade do preço da cultura também afeta a área plantada de um ano para o outro. $O$ uso da irrigação é necessário para manter a qualidade e a produtividade da cultura do feijão (Klar \& Fernandes, 1997).

A quantidade de água utilizada pela irrigação tem se tornado uma preocupação recente, tendo em vista o elevado preço dos equipamentos como também da energia necessária para a aplicação de água. Aplicações de água em excesso causam percolação profunda e lixiviação dos nutrientes, promovendo desta forma o incremento do custo de produção agrícola e contaminação dos suprimentos de água. A competição entre irrigantes e outros usuários pelo mesmo suprimento de água reduz a disponibilidade de água para a irrigação. $\mathrm{O}$ manejo adequado da irrigação reduz os custos da aplicação de 
água, conserva os mananciais e reduz a probabilidade de problemas com a qualidade da água.

O manejo da irrigação requer estimativas diárias da evapotranspiração da cultura com uma precisão comparável a uniformidade de aplicação de água pelo sistema de irrigação. Vários métodos para o manejo da irrigação tem sido utilizados. Os métodos indiretos, que se baseiam no solo, consideram-no como um reservatório, capaz de conter certa quantidade de água. Os métodos meteorológicos utilizam basicamente informações meteorológicas, como entradas de dados para modelos que calculam a quantidade de água evapotranspirada pela cultura durante um certo período. Recentemente, medidas diretas de alguns indicadores da planta com o objetivo de caracterizar sua necessidade de água estão sendo estudados.

Segundo Doorenbos \& Kassam (1979), o feijoeiro requer entre 300 a $500 \mathrm{~mm}$ de água para atingir seu rendimento máximo, dependendo do clima, para ciclos entre $60 \mathrm{e}$ 120 dias. Quando estas necessidades não são satisfeitas, o rendimento se reduz a um valor dependente da etapa fenológica em que o déficit de água acontece. Quando a seca se apresenta na etapa vegetativa, por exemplo, o efeito sobre o crescimento é mínimo, enquanto que na etapa de pré-floração e enchimento de vagens, a planta é muito sensível a falta de água no solo.

A evapotranspiração atual da cultura (ETc) é, geralmente, uma fração da evapotranspiração de referência (ETo). Depende da cobertura vegetal da superficie do solo, especialmente da superficie foliar para a transpiração, e da quantidade de água no solo. A evapotranspiração máxima de uma cultura (ETm) foi definida por Doorenbos \& Kassam (1979) como a evapotranspiração de uma cultura livre de doenças, desenvolvendo-se num campo sem restrição de água ou fertilidade do solo e que é capaz de atingir a máxima produção potencial sob determinadas condições climáticas.

A ETc do feijoeiro tem sido avaliada por vários pesquisadores. Reichardt et al. (1974) utilizando o método do balanço hídrico, registraram para as condições de 
Piracicaba - SP, uma evapotranspiração real média de $3,45 \mathrm{~mm} \cdot$ dia $^{-1}$, durante 48 dias do ciclo. $\mathrm{O}$ balanço hídrico fornece uma boa estimativa da evapotranspiração sob condições de alta demanda atmosférica e baixa precipitação, entretanto, se o armazenamento da água no solo não for positivo, o balanço hídrico não pode ser aplicado. Outro problema deste método é a determinação da drenagem profunda (Black et al., 1970).

Encarnação (1980) verificou que o tanque "Classe A" apresentou a melhor estimativa da demanda de água para a cultura do feijão em Piracicaba - SP em comparação com outros métodos de estimativa, e os valores de Kc foram próximos dos sugeridos por Doorenbos \& Kassam (1979).

O fator que relaciona a ETm com a ETo é o coeficiente de cultura Kc, que varia com o estádio da cultura, as condições climáticas e o comprimento do seu ciclo. Quando não existe deficiência de água no campo, a ETa é igual à ETm. Allen et al. (1990) sugeriram que os valores de coeficiente de cultura (Kc) sejam determinados empiricamente para cada cultura baseados em dados de lisímetro e nas condições climáticas locais. Coeficientes de cultura $(\mathrm{Kc})$ sugeridos por Doorenbos \& Kassam (1979) tem sido utilizados para inúmeras culturas sob as mais diversas condições climáticas. Contudo, muitas vezes, esses coeficientes não têm revelado de maneira satisfatória as verdadeiras condições da evapotranspiração da cultura para um determinado local e uma cultura específica.

Embora muitos modelos de estimativa da evapotranspiração sejam propostos. $\mathbf{O}$ aumento da disponibilidade de dados climáticos tem gerado um grande interesse em modelos que são capazes de estimar a evapotranspiração diária integrando variáveis ambientais coletadas em pequenos intervalos de tempo. $O$ método do Balanço de energia utilizando a razão de Bowen tem sido empregado com muito sucesso em muitos estudos (Tanner, 1960; Villa Nova, 1973; Sinclar et al., 1975; Bergamaschi et al., 1988.). O principal objetivo deste estudo foi de mensurar e relacionar a evaportanspiração da 
cultura do feijão (Phaseolus vulgaris L.) e a evapotranspiração de referência utilizando o método do Balanço de energia e o lisímetro de pesagem para as condições de campo.

\subsection{Material e Métodos}

O-experimento foi conduzido em condições de campo, na área experimental do Departamento de Engenharia Rural - ESALQ/USP, situada no município de Piracicaba SP, nas seguintes coordenadas geográficas: $22^{\circ} 42^{\prime} 30^{\prime \prime}$ de latitude Sul; $47^{\circ} 30^{\prime} 00^{\prime \prime}$ de longitude Oeste; e a 546 metros de altitude.

Segundo a classificação climática de Köeppen, Piracicaba possui clima do tipo Cwa, ou seja, subtropical úmido, com estiagem no inverno, com temperatura média no mês mais frio inferior a $18{ }^{\circ} \mathrm{C}$ e no mês mais quente superior a $22{ }^{\circ} \mathrm{C}$. A temperatura média anual é de $21,1^{\circ} \mathrm{C}$ e a precipitação média anual é de aproximadamente $1250 \mathrm{~mm}$.

Uma parcela experimental de 3,5 ha irrigada por pivô central, cultivada com a variedade IAC carioca Pyatã (ciclo de 98 a 105 dias), foi semeada em 13 de agosto de 1998 , com espaçamento entre linha de $0,60 \mathrm{~m}$ e densidade de $12 \mathrm{plantas} / \mathrm{m}^{2}$. A cultura do feijão recebeu adubação (base e cobertura) conforme análise do solo e o controle fitosanitário foi realizado de acordo com as recomendações técnicas para a cultura. Durante o período de desenvolvimento foram feitas observações fenológicas e medidas do índice de área foliar (IAF), num intervalo médio de sete dias.

Os dados sobre a superficie gramada foram obtidos no Posto Agrometeorológico $\left(3.150 \mathrm{~m}^{2}\right)$ na área experimental do Departamento de Engenharia Rural. As duas áreas foram irrigadas freqüentemente, além disso as chuvas naturais serviram para manter as condições de umidade do solo ideais a evapotranspiração potencial.

Durante o transcorrer do experimento foram realizadas medições micrometeorológicas para fornecer valores médios em intervalos de tempo de 20 minutos sobre a cultura (feijão e gramada). A temperatura do ar $\left({ }^{\circ} \mathrm{C}\right)$ e a umidade absoluta $\left(\mathrm{g} / \mathrm{cm}^{3}\right)$ 
foram mensuradas nos níveis 0,25 e $1,0 \mathrm{~m}$ na cultura do feijão e 0,10 e $1,5 \mathrm{~m}$ na superficie gramada. A radiação líquida $\left(\mathrm{W} / \mathrm{m}^{2}\right)$ e o fluxo de calor no solo $\left(\mathrm{W} / \mathrm{m}^{2}\right)$ também foram mensurados. Estes dados foram obtidos utilizando um sistema automático de razão de Bowen fabricado pela Campbell Scientific. A partir das medições de radiação líquida $(\mathrm{Rn})$, fluxo de calor no solo $(\mathrm{G})$, diferenças de temperatura e pressão de vapor entre dois níveis o balanço de energia pode ser apresentado como:

$\mathrm{Rn}-\mathrm{G}-\mathrm{H}-\mathrm{LE}=0$

em que Rn é a radiação líquida; $\mathrm{G}$ é o fluxo de calor no solo; $\mathrm{H}$ é o fluxo de calor sensível; e LE é o fluxo de calor latente.

O método da razão de Bowen (Bowen, 1926) estima os fluxos de calor sensível e latente baseado na resolução da equação do balanço de energia considerando a razão de Bowen $(\beta=\mathrm{H} / \mathrm{LE})$

$L E=-\frac{(R n+G)}{(1+\beta)}$

A razão de Bowen ( $\beta$ ) foi calculada a partir da equação

$\beta=\gamma \frac{\Delta T}{\Delta \mathrm{e}}$

em que $\gamma$ é a constante psicrométrica; $\Delta \mathrm{T}$ é a diferença de temperatura entre dois níveis sobre a superficie; $\Delta$ e é a diferença de pressão de vapor para os mesmos dois níveis. $\mathbf{O}$ fluxo de calor sensível foi determinado utilizando a equação (1). Os valores de evapotranspiração foram estimados usando as equações (2) e (3).

A medida direta da evapotranspiração da cultura (ETc) e da evapotranspiração de referência (ETo) foi feita utilizando lisímetros de pesagem. Na área cultivada com a cultura do feijão foi utilizado um lisímetro com as seguintes dimensões: $0,70 \mathrm{~m}$ de profundidade, $1,50 \mathrm{~m}$ de comprimento e $1,30 \mathrm{~m}$ de largura. $\mathrm{Na}$ área vegetada com grama 
foi construído um lisímetro de $0,70 \times 1,0 \times 1,0 \mathrm{~m}$. Detalhes da construção deste equipamento podem ser observado em Silva (1999).

Os mesmos tratos culturais (adubação, irrigação, etc) foram utilizados dentro e fora dos lisímetros para assegurar a uniformidade de desenvolvimento da cultura e efeitos adversos a uma condição de evapotranspiração potencial.

A evapotranspiração da cultura (ETc) e a evapotranspiração de referência (ETo) foram mensuradas pelo método do Balanço de energia e pelo lisímetro de pesagem. $\mathbf{O}$ coeficiente de cultura $(\mathrm{Kc})$ foi estimado segundo as equações:

$$
\mathrm{kc}_{\text {Bowen }}=\frac{\mathrm{ETc}_{\text {Bowen }}}{\mathrm{ETo}_{\text {Bowen }}}
$$

e

$$
\mathrm{kc}_{\text {Lisimetro }}=\frac{\mathrm{ETc}_{\text {Lisimetro }}}{\mathrm{ETo}_{\text {Lisimetro }}}
$$

em que $\mathrm{Kc}_{\text {Bowen }}$ é o coeficiente de cultivo utilizando os valores mensurados pelo método do Balanço de energia; e $\mathrm{Kc}_{\mathrm{Lisimetro}}$ é o coeficiente de cultivo utilizando os valores mensurados pelo lisímetro de pesagem.

\subsection{Resultados e Discussão}

Os diferentes valores da evapotranspiração podem ser relacionados com as diferentes fases de desenvolvimento da cultura e a disponibilidade de energia. Os valores do índice de área foliar (IAF) estão apresentados na Figura 1. O período com maior taxa de incremento ocorreu 35 dias após o plantio, correspondendo a fase de florescimento. 


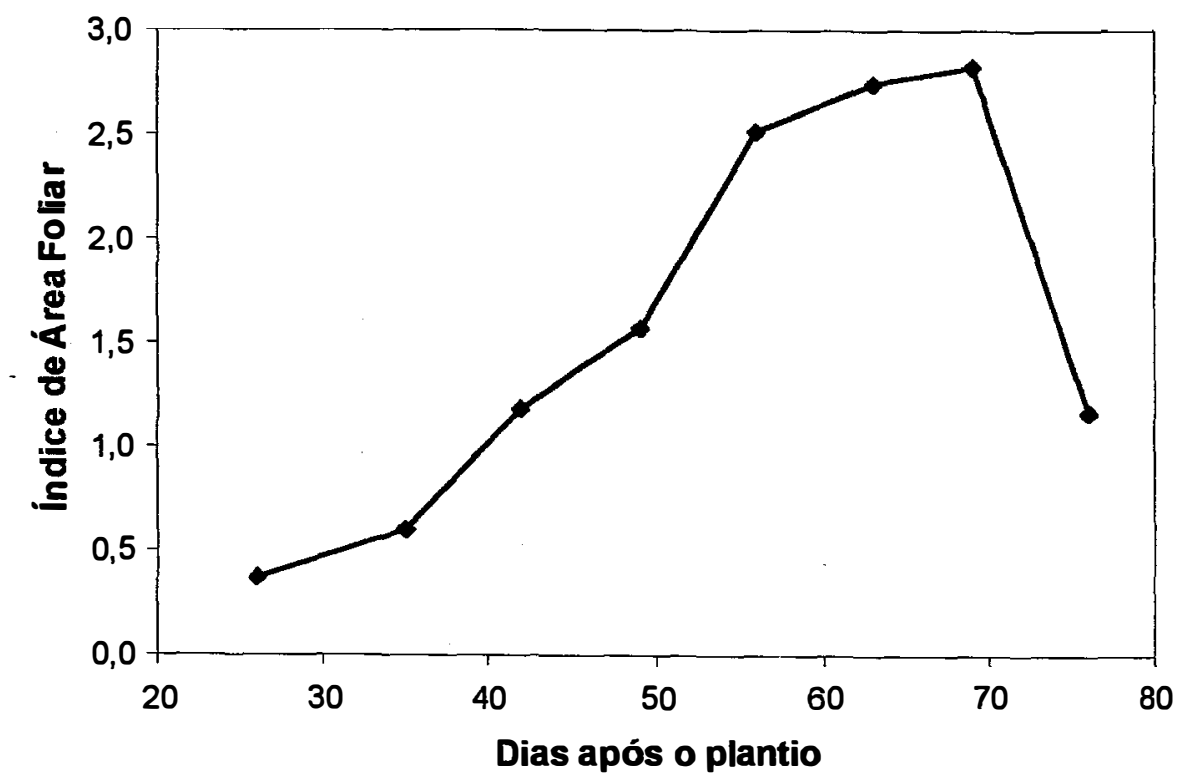

Figura 1 - Índice de área foliar para a cultura do feijão (phaseolus vulgaris $L$.), durante o período do experimento. Piracicaba - SP.

A evapotranspiração média da cultura (ETc) estimada pelo método do Balanço de energia foi de 4,36 mm.dia ${ }^{-1}$, ou 130,82 mm para o período de observação; os valores de ETc mensurados pelo lisímetro de pesagem foram de $5,05 \mathrm{~mm}$.dia ${ }^{-1}$ ou $151,36 \mathrm{~mm}$. A evapotranspiração de referência (ETo) obtida para o mesmo período sobre uma superficie gramada apresentou valores de 5,19 mm.dia ${ }^{-1}$ e $155,66 \mathrm{~mm}$ no total utilizando o método do Balanço de energia; o lisímetro de pesagem apresentou um valor médio de ETo igual a $6,22 \mathrm{~mm} \cdot \mathrm{dia}^{-1}$ e um total de $186,63 \mathrm{~mm}$.

Os valores da evapotranspiração da cultura (ETc) e evapotranspiração de referência encontrados no presente trabalho foram menores do que os apresentados em outros estudos (Garrido \& Teixeira, 1978; Costa, 1986). A baixa demanda atmosférica durante o ciclo da cultura pode ser um dos fatores que influenciarão os resultados.

Os valores diários de evapotranspiração da cultura (ETc) e evapotranspiração de referência (ETo) estimado pelo método do Balanço de energia e pelo lisímetro de pesagem para o período de observação são apresentados na Figura 2. $O$ método do 
Balanço de energia e o lisímetro de pesagem apresentaram uma mesma tendência em relação as variações das condições meteorológicas diárias durante o período de observação. Entretanto diferenças entre os valores obtidos pelos dois métodos foram observadas. A evapotranspiração total mensurada pelo método do Balanço de energia foi subestimada em $20 \%$ para a ETo e $15 \%$ para a ETc. De acordo com Prueger et al. (1997), a razão para esta subestimativa está relacionada com a condição de umidade dentro do lisímetro próxima a saturação. $\mathbf{O}$ incremento da evapotranspiração medida pelo lisímetro pode ser devido a um aumento na evaporação da água no solo ou da transpiração da planta. Entretanto, não é possível separar esses dois processos com uma mensuração simples.
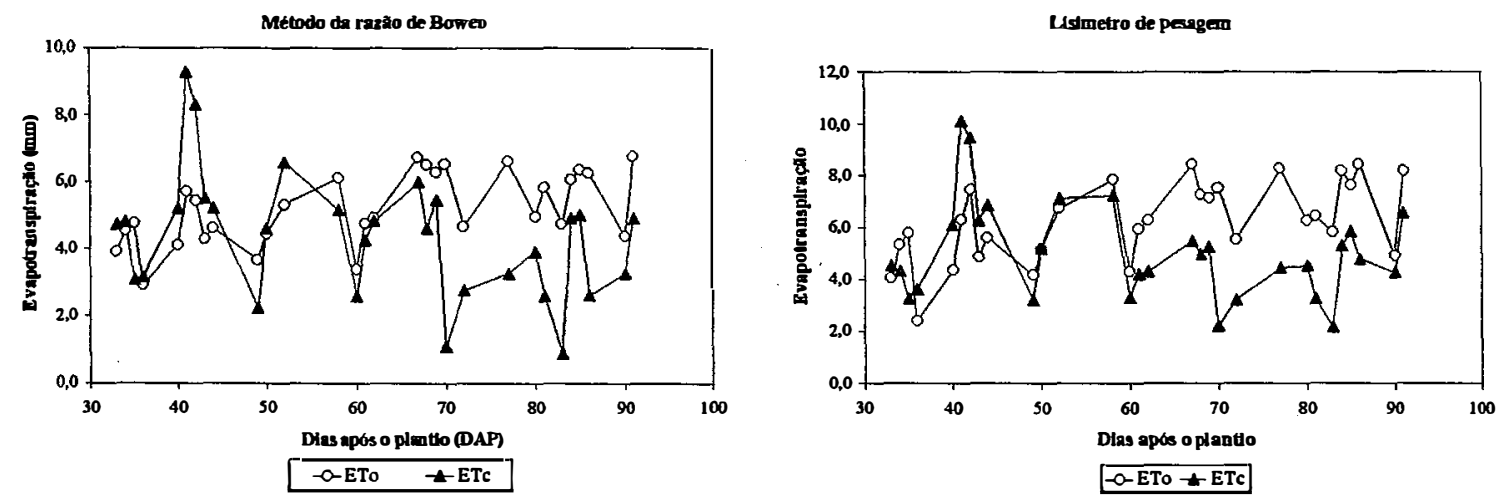

Figura 2 - Evapotranspiração da cultura diária (ETc) e evapotranspiração de referência diária (ETo) obtida pelo método do Balanço de energia e o lisímetro de pesagem durante o período de observação. Piracicaba - SP.

O coeficiente de cultivo $(\mathrm{Kc})$ é muito utilizado no planejamento e manejo da irrigação para estimativa de valores da evapotranspiração das culturas. Os valores dos coeficientes de cultivo $(\mathrm{Kc})$ obtidos para a cultura do feijão utilizando os valores de evapotranspiração medidos pelo método do Balanço de energia e o lisímetro de pesagem as apresentados na Tabela 1. 
Tabela 1 - Valores médios por estádio, a partir do $31^{\circ}$ dia após o plantio, dos coeficientes de cultura Kc estimados para a cultura do feijão as estimativas de evapotranspiração pelos métodos da razão de Bowen e o lisímetro de pesagem. Piracicaba - SP.

\begin{tabular}{|c|c|c|c|c|c|c|c|}
\hline \multirow[b]{2}{*}{ Fase } & \multirow[b]{2}{*}{$\begin{array}{c}\text { Dias } \\
\text { após o } \\
\text { plantio }\end{array}$} & \multicolumn{2}{|c|}{ Bowen } & \multicolumn{2}{|c|}{ Lisímetro } & \multirow[b]{2}{*}{$\begin{array}{c}\text { Kc } \\
\text { Bowen }\end{array}$} & \multirow[b]{2}{*}{$\begin{array}{c}\text { Kc } \\
\text { Lisímetro }\end{array}$} \\
\hline & & $\begin{array}{c}\text { ETc } \\
\left(\mathrm{mm} \cdot \mathrm{dia}^{-1}\right)\end{array}$ & 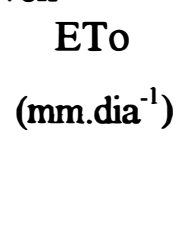 & $\begin{array}{c}\text { ETc } \\
\left(\mathrm{mm} \cdot \operatorname{dia}^{-1}\right)\end{array}$ & $\begin{array}{c}\text { ETo } \\
\left(\mathrm{mm} \cdot \mathrm{dia}^{-1}\right)\end{array}$ & & \\
\hline Vegetativo & $31-43$ & 5,52 & 4,46 & 5,96 & 5,07 & 1,24 & 1,17 \\
\hline Florescimento & $44-81$ & 4,07 & 5,34 & 4,67 & 6,43 & 0,76 & 0,73 \\
\hline Maturação. & $82-92$ & 3,60 & 5,76 & 4,82 & 7,20 & 0,62 & 0,67 \\
\hline
\end{tabular}

Os coeficientes de cultura $(\mathrm{Kc})$ foram 1,24 e 1,17 para a fase vegetativa, 0,76 e 0,73 para a fase de florescimento e formação de vagem e 0,62 e 0,67 para a fase de maturação e 0,85 e 0,84 para todo o ciclo, respectivamente, baseados no método do Balanço de energia e do lisímetro de pesagem. De maneira geral, os valores de $\mathrm{Kc}_{\text {Bowen }} \mathrm{e}$ $\mathrm{Kc}_{\text {lisimetro }}$ não apresentaram diferenças significativas. Entretanto, os valores de $\mathrm{Kc}$ encontrados diferem de maneira considerável dos sugeridos por Doorenbos e Kassam (1979). Os elevados valores de Kc durante a fase vegetativa podem estar relacionados com a ocorrência de chuvas durante o período o que acarretou em uma maior disponibilidade de água para a evapotranspiração.

Luchiari Junior (1978) mensurou a evapotranspiração da cultura do feijão em Piracicaba - SP através do método do balanço hídrico de campo e descobriu valores médios de $\mathrm{ETc}=3,06 \mathrm{~mm}$. dia ${ }^{-1} \mathrm{e} \mathrm{Kc}=0,88$ para todo o ciclo. $\mathrm{O}$ valor do coeficiente de cultura para todo ciclo encontrado por este autor foi próximo ao valor encontrado no presente trabalho.

Na Figura 3 é apresentada a variação dos valores do coeficiente da cultura do feijão durante todo o ciclo observado. Na fase logo após o início da fase vegetativa foi possível identificar um pequeno aumento no valor do Kc devido ao baixo valor de IAF. 
$\mathrm{Na}$ fase de florescimento ocorreu um aumento do valor do Kc devido ao incremento do IAF. Durante a fase de maturação houve um decréscimo dos valores do Kc em função da senescência da cultura.

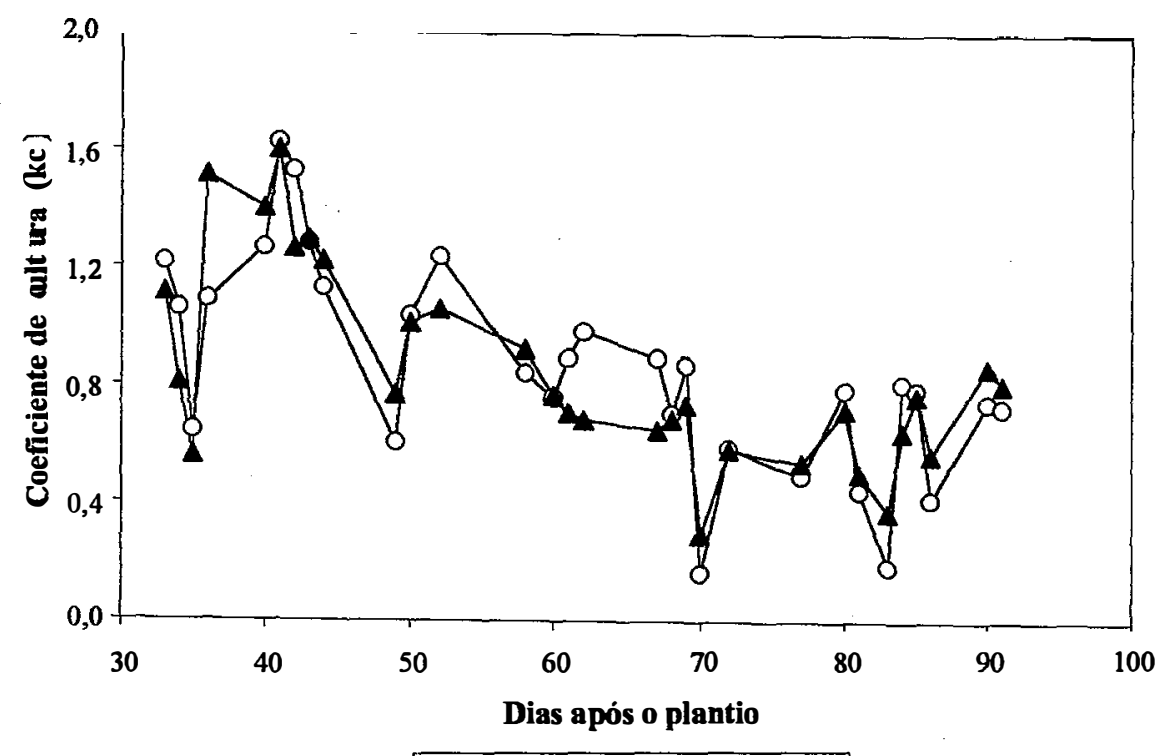

- - kc Bowen - - kc Lisimetro

Figura 3 - Valores do coeficiente de cultura $(\mathrm{Kc})$ obtido pelo método do Balanço de energia e do lisímetro de pesagem para todo o ciclo da cultura do feijão. Piracicaba - SP.

Encarnação (1980), estudando a mesma cultura na mesma localidade, utilizando o método do tanque "Classe $A$ " encontrou valores de $\mathrm{Kc}=0,70$ para fase vegetativa e 1,40 para fase de florescimento e formação de vagem. A baixa demanda atmosférica durante $o$ ciclo da cultura pode ter causado um decréscimo da evapotranspiração da cultura e conseqüentes diferenças nos valores de Kc encontrados em relação aos observados no trabalho de Encarnação (1980).

É importante lembrar que o clima, a planta e o solo são importantes fatores que controlam a evapotranspiração das culturas, a demanda atmosférica, principalmente quando sob ótimas condições de umidade no solo. No caso particular deste experimento, 
não ocorreu restrições de umidade no sistema solo-planta em relação ao uso de água para o desenvolvimento da cultura.

\subsection{Conclusões}

A evapotranspiração da cultura do feijão na localidade de Piracicaba - SP obtida foi de 4,36 mm.dia ${ }^{-1}$., ou 130,82 mm para o período de observação e $5,05 \mathrm{~mm} \cdot \mathrm{dia}^{-1}$ ou 151,36 mm, respectivamente pelo método do Balanço de energia e lisímetro de pesagem.

A evapotranspiração de referência (ETo) obtida para o mesmo período sobre uma superficie gramada apresentou valores $5,19 \mathrm{~mm} \cdot \mathrm{dia}^{-1}$ e $155,66 \mathrm{~mm}$ no total utilizando o método da razão de Bolem; o lisímetro de pesagem apresentou um valor médio de ETo igual a $6,22 \mathrm{~mm} \cdot \mathrm{dia}^{-1}$ e um total de $186,63 \mathrm{~mm}$.

Os coeficientes de cultura (Kc) foram 0,85 e 0,84 para todo o ciclo, respectivamente, baseados no método do Balanço de energia e do lisímetro de pesagem. De maneira geral, o valor de $\mathrm{Kc}_{\mathrm{Bowen}} \mathrm{e} K \mathrm{c}_{\text {lisimetro }}$ não apresentaram diferença significativa.

Os valores de coeficiente de cultura diferiram de maneira considerável em relação ao sugeridos pela FAO. Desta forma é necessária uma calibração local para obtenção destes valores.

A utilização de métodos de estimativa da evapotranspiração que utilizam variáveis ambientais com aquisição automática de dados em tempo real, como o método do Balanço de energia pode provir bons resultados em relação a dispositivos lisimétricos. 


\section{CONCLUSÕES GERAIS}

Com base nas informações coletadas e analisadas no presente trabalho foram estabelecidas as seguintes conclusões:

A quantidade de energia utilizada no fluxo de calor latente de evaporação (evapotranspiração) foi influenciada pelo índice de área foliar e pela demanda evaporativa da atmosfera. A menor porção da radiação líquida foi utilizada no aquecimento do solo, sendo influenciado pela cobertura vegetal.

Para o período estudado, obteve-se os seguintes valores para evapotranspiração da cultura do feijão: ET Lisímetro $=151,36 \mathrm{~mm}$ e ET Balanço de energia $=130,82 \mathrm{~mm}$. Sendo que o método do Balanço de energia subestimou a evapotranspiração com relação ao lisímetro de pesagem em cerca de $16 \%$.

Considerando a variação normal das condições ambientais, verificou-se concordância e consistência das técnicas (Balanço de energia e Lisímetro de pesagem) na determinação da evapotranspiração.

A utilização de métodos de estimativa da evapotranspiração que utilizam variáveis ambientais com aquisição automática de dados em tempo real, como o método do Balanço de energia pode prover bons resultados em relação a dispositivos lisimétricos.

A relação entre $Q g$ / Rn, nas diferentes fases fenológicas da cultura do feijão, variou (decresceu) com o aumento do índice de área foliar; 
A radiação líquida, para efeito de elaboração de projetos de irrigação, pode ser estimada satisfatoriamente por regressão, em função da radiação global;

A radiação liquida da superficie gramada foi inferior à radiação líquida disponível para uma superficie vegetada pela cultura de feijão.

A evapotranspiração da cultura do feijão na localidade de Piracicaba - SP obtida foi de 4,36 mm.dia ${ }^{-1}$, ou 130,82 mm para o período de observação e $5,05 \mathrm{~mm}^{-1 a^{-1}}$ ou $151,36 \mathrm{~mm}$, respectivamente pelo método do Balanço de energia e lisímetro de pesagem.

A evapotranspiração de referência (ETo) obtida para o mesmo período sobre uma superficie gramada apresentou valores $5,19 \mathrm{~mm} \cdot \mathrm{dia}^{-1}$ e $155,66 \mathrm{~mm}$ no total utilizando o método do Balanço de energia; o lisímetro de pesagem apresentou um valor médio de ETo igual a 6,22 mm.dia ${ }^{-1}$ e um total de $186,63 \mathrm{~mm}$.

Os coeficientes de cultura médios $(\mathrm{Kc})$ foram 0,85 e 0,84 para todo o ciclo, respectivamente, baseados no método do Balanço de energia e do lisímetro de pesagem. De maneira geral, o valor de $\mathrm{Kc}_{\text {Bowen }}$ e $\mathrm{Kc}_{\text {lisimero }}$ não apresentaram diferença significativa

Os valores de coeficiente de cultura diferiram de maneira considerável em relação ao sugeridos pela FAO. Desta forma é necessária uma calibração local para obtenção destes valores. 


\section{REFERÊNCIAS BIBLIOGRÁFICAS}

ALLEN, R. G., JENSEN, M. E., BURMAN, R. D. Evapotranspiration and irrigation water requirement. ASCE Manual and Report on Engineering Practice, n. 70. American Society of Civil Engineers, New York, USA, 123 p.

BERGAMASCHI, H.; OMETTO, J. C.; VIEIRA, H. J. et al. Deficiência hídrica em feijoeiro, II Balanço de energia. Pesquisa Agropecuária Brasileira, Brasília, v.1, n.1, p. 745-757. 1988

BERLATO, M. A.; MOLION, L. C. B. Evaporação e evapotranspiração. Porto Alegre: IPAGRO, 1981. 95p. ( IPAGRO. Boletim Técnico, 7 ).

BLACK, T.A.; GARDNER, W.R.; TANNER, C.B. Water storage and drainage under a row crop on a sandy soil. Agronomy Journal, v.62, p.48-51, 1970.

BLAD, B. L.; ROSENBERG, N. J. Lysimetric calibration of the Bowen ratio-energy balance method for evapotranspiration estimation in the central great plains. Journal applied Meteorology . Vol. 13, p. 227-236. 1974

BLANEY, H. F.; CRIDDLE, W. D. Determining water requirements in irrigated areas from climatological and irrigation data. Washington: USDA, 1950. 48p.

BOWEN, I. S. The ratio of heat losses by conduction and by evaporation from any water surface, Physical Review. New York, v. 27, p. 779-787. 1926.

BRUTSAERT, W. Evaporation into the atmosfere: theory, history and applications. Dordrecht: Kluver Academic, 1982. 299p. (Environmental Fluid Mechanics, 1). 
BROUGHAM, R. W. Interception of light by foliage of pure and mixed stands of pasture plants. Australian Journal Agricultural Reasearch, v. 9, p. 39-52, 1958.

BUliSANI, E. A.; ALMEIDA, L. D. A.DE; ROSTON, A. J. a CULTURA DO FEIJOEIRO NO Estado de São Paulo. In: BULISANI, E. A. (Coord.). Feijão: fatores de produção e qualidade. Campinas, Fundação Cargill, 1987. P29-88.

BURMAN, R. D. ; NIXON, P. R. ; WRIGTH, J. L. ; PRUTTT, W. O. Water requirements. In: JENSEN, M. E., ed. Design and operation of farm irrigation system. St. Joseph: ASAE, 1983. cap. 6, p. 189-232.

CAIXETA, T. J. Irrigação do feijoeiro. Informe Agropecuário, v.4, n.46, p.36-40, 1978.

CAMARGO, A.P. Contribuição para a determinação da evapotranspiração potencial do estado de São Paulo. Campinas: Instituto Agrônomico de Campinas, 1961. 56p. (IAC. Circular Técnica, 161).

CAMPECHE, L. F. S. M. Estimativa da resistencia de dosel (rc) da grama com uso da termometria ao infravermelho. Piracicaba, 1997. 52p. Dissertação (Mestrado) Escola Superior de Agricultura "Luiz de Queiroz", Universidade de São Paulo.

COSTA, A.C.S. Balanço hídrico em culturas de feijão (Phaseolus vulgaris L.) e de milho (Zea mays L.) sob condições de campo. Piracicaba, 1986. 143p. Dissertação (Mestrado) - Escola Superior de Agricultura "Luiz de Queiroz", Universidade de São Paulo.

DECKER, W. L. Variations in the net exchange of radiation from vegetative of different heigths. Journal Geophysic Resource. V. 64, p. 1617-1619, 1959.

DOORENBOS, J.; KASSAM, A.H. Efectos del agua en el rendimiento de los cultivos. Roma: FAO, 1979. 212p. (Estudio FAO: Riego y Drenaje, 33) 
DOORENBOS, J.; PRUITT, J. O. Guidlines for predicting crop water requirements. Rome: FAO, 1977. 179p. (FAO Irrigation and Drainage Paper, 24).

ENCARNAÇÃO, C.R.F. Estudo da demanda de água do feijoeiro (P. vulgaris L. var. Goiano Precoce). Piracicaba, 1980. 62p. Dissertação (Mestrado) - Escola Superior de Agricultura "Luiz de Queiroz", Universidade de São Paulo.

FANCELLI, A. L. Fenologia e exigências climáticas do feijoeiro. In: FANCELI, A. L.; COORD. Feijão irrigado. Piracicaba. FEALQ; ESALQ/USP. Departamento de Agricultura. 1990. p. 7-24.

FANCELLI, A. L.; DOURADO-NETO, D. Ecofisologia e Fenologia do Feijoeiro. In: FANCELLI, A. L.; \& DOURADO-NETO, D., COORD. Tecnologia da produção do feijão irrigado. Piracicaba: ESALQ/USP, Departamento de Agricultura, 1997. p. 100120.

FERNÁNDEZ, F.; GEPTS, P.; LÓPEZ, M. Etapas de desarrollo de la planta de frijol común. Guia de estudio para ser usada como complemento de la unidad audiotutorial sobre el mismo tema. Cali, Colômbia. 1982. 26 p.

FNP CONSUlTORIA \& COMÉRCIO. Agrianual 98: Anuário Estatístico da Agricultura Brasileira. São Paulo. 481 p.

FRITSHEN, J. L. Accuracy of Evapotranspiration determination by the Bowen ratio method. Bull. Intern. Assoc. Sci. Hydrol. V. 10, p. 38-48, 1965

FONTANA, D. C.; BERLATO, M. A. BERGAMASCHI, H. Balanço de energia em soja irrigada e não irrigada. Pesquisa Agropecuária Brasileira, v. 3, n. 26, p. 403-410, 1991.

FUCHS, M.; TANNER, C. B. Error analysis of Bowen ratios measured by differential psychrometry. Agricultural Meteorology. V. 7, p. 329-334, 1970. 
GARRIDO, M.A.T.; TEIXEIRA, H.A. Efeito de diferentes níveis de umidade do solo sobre o rendimento do feijoeiro comum na região sul de Minas Gerais. In EPAMIG. Projeto Feijão. Belo Horizonte, 1978. 15p. (Relatório 75/76).

GARRIDO, M. A. T.; PURCINO, J. R. C.; LIMA, C.A.S. Efeitos de diferentes regimes de irrigação sobre o rendimento do feijoeiro na região Norte de Minas Gerais. In: EPAMIG. Projeto Feijão. Belo Horizonte, 1979. P 27-29. (relatório 77/78).

GUIMARĀES, C. M. Características morfo-fisiológicas do feijoeiro (Phaseolus vulgaris L.) relacionadas com a resistência à seca. Campinas, 1992. 131 p. Tese (Doutorado) Instituto de Biologia, UNICAMP.

GEPTS, P.; FERNÁNDEZ, F. Etapas de desarrollo de la planta de frijol comum (Phaseolus vulgaris L.) Cali, Colombia, Ciat, 1982. 10 p. (mimeografado)

HARGREAVES, G. H. Water requirements manual for irrigated crop,and rainfed agriculture. Logan: Utah State University, 1977. 41p.

HATFIELD, J. L. Research priorities in ET: evolving methods. Transactions of the ASAE, v.31, n.2, p. 491-5, 1988.

JENSEN, M. E. Consumptive of water and irrigation water requirements. New York: ASCE, 1973. 215p.

JENSEN, M. E.; HAISE, H. R. Estimating evapotranspiration from solar radiation. Journal of Irrigation an Drainage Engineering, v. 89, p. 15-41, 1963.

JENSEN, M.E.; BURMAN, R.D.; ALLEN, R.G. Evapotranspiration and irrigation water requeriments. New York: ASCE, 1990. 332p.

KLAR, A. E.; FERNANDES, M.A. Water needs for winter bean crop. Scientia Agricola, vol. 54, n.3. 11p. 1997. 
LEMON, E. R.; GLASER, A. H.; SATTERWHITE, L. E. Some aspects of the relationship of soil, plant and meteorological factors to evapotranspiration. Soil Science Society of American Proceedings. v.21, n.5, p. 464-8, 1957.

LLASAT, M. C.; ZINDER, R. L Data error effects on net radiation and Evapotranspiration estimation. Agricultural and Forest Meteorology. V. 91, p. 209221, 1998.

LUCHIARI JUNIOR, A. Determinação do coeficiente de cultura $(\mathrm{Kc})$ para feijão (P. vulgaris, L.) pelo método do balanço hídrico. Piracicaba, 1978. 59p. Dissertação (Mestrado) - Escola Superior de Agricultura "Luiz de Queiroz", Universidade de São Paulo.

LUCHIARI Jr., A. Measurements and predictios of evapotranspiration rates from irrigated wheat in the Cerrado region of central Brazil. Ithaca, 1988. 171p. Tese ( Phd) - Cornell University.

LUCHIARI Jr., A.; RIHA, S. J. Bulk surface resistance and its effect on evapotranspiration rates in irrigated wheat. Agronomy Journal, v. 83 , p. $888-95,1991$.

MAGALHÃES, A. C.; CARELLI, M. L. Germinação de sementes de feijão (Phaseolus vulgaris $L$.) sob condições variadas de pressão osmótica. Bragantia, v.31, n. 32, p. 19-26, 1972.

MAGGIOTTO, S. R. Estimativa da evapotranspiração de referência pelo uso da termometria ao infravermelho. Piracicaba, 1996. 71p. Dissertação (Mestrado) Escola Superior de agricultura "Luiz de Queiroz", Universidade de São Paulo.

MILLAR, B. D. Effect of local advection on evaporation and plant water status. Australian Journal of Agriculture,v. 25, p. 97-106, 1964. 
MONTEITH, J. L. Evaporation and environment. In: SYMPOSIUM OF THE SOCIETY FOR EXPERIMENTAL BIOLOGY, London, 19. ,Swansea, 1964. Cambridge: Cambridge University Press, 1965. p. 205-34.

MONTEITH, J. L. Evaporation from land surfaces: progress in analysis and prediction since 1948. In: NATIONAL CONFERENCE ON ADVANCES IN EVAPOTRANSPIRATION, Chicago, 1985. Proceedings. St. Joseph: ASAE, 1985. p. 4-12.

MOREIRA, J. A. A.; STONE, L. F. Manejo de solo-planta e avaliação sócioeconômica dos sistemas agrícolas irrigados por aspersão na região dos cerrados. Goiânia: EMBRAPA-CNPAF, 1995. V.1 (EMBRAPA. Projeto 04.095.273.06)

NORMAN, J. M.; CAMPBELL, G. Application of a plant-environment model to problems in irrigation. In: HILLEL, D. Advances in irrigation. New York: Academic Press, 1983. v. 2, p. 155-88.

OKE, T. R. Boundary layer climates. 2. ed. London: Routledge, 1992. 435p.

OMETTO, J. C. Estudo das relações entre radiação solar global, radiação líquida e insolação. Piarcicaba, 1968. 64 p. Tese (Doutorado) - Escola Superior de Agricultura “Luiz de Queiroz', Universidade de São Paulo.

OMETTO, J. C. Bioclimatologia vegetal. São Paulo: Agronômica Ceres, 1981. 440p.

PELTON, W. L.; KING, K. M.; TANNER, C. B. An evaluation of the Thornthwaite and mean temperature methods for determining potential evapotranspiration. Agronomy Journal, v.52, n.7, p. 387-95, 1960.

PENMAN, H. L. Natural evaporation from open water, bare soil and grass. Proceedings Royal Society of London. Serie A, v. 193,p. 120-45, 1948. 
PENMAN, H. L. Evaporation: Introduction survey. Netherlands Journal of Agricultural Science. v.4, n. 1, p.9- 29, 1956.

PEREIRA, A. R. Análise do modelo de Priestley e Taylor para estimativa da evapotranspiração potencial. Piracicaba, 1990. 68p. Tese (Livre-docência) - Escola Superior de Agricultura "Luiz de Queiroz", Universidade de São Paulo.

PEREIRA, A. R.; VILLA NOVA, N.; SENTELHAS, P. C. Evapo(transpi)ração. Piracicaba: FEALQ, 1997. 183p.

PERES, J. G. Avaliação do modelo de Penman-Monteith, padrão FAO, para estimar a evapotranspiração de referência nas condições climáticas do estado de São Paulo. Piracicaba, 1994. 116 p. Tese (Doutorado) - Escola Superior de Agricultura "Luiz de Queiroz", Universidade de São Paulo.

PORTES, T. de A. Ecofisiologia . In: ARAÚJO, R. S.; RAVA, C. A.; STONE, L. F.; ZIMMERMANN, M. J. DE O. (CORRD.). Cultura do Feijoeiro Comum no Brasil. Piracicaba: POTAFOS, 1996. P 101-137.

PRIESTLEY,C. H. B.; TAYLOR, R. J. On the assessment of surface heat flux and evaporation using large-scale parameters. Monthly Weather Review., v. 100, p. 81$2,1972$.

PRUEGER, J. H.; SAUER, T. J.; HATFIELD, J. L. Turbulence flux of sensible and latent heat near shelterbelts during low wind conditions. Transactions of the ASAE. Saint Joseph. Vol. 41, n. 6, p. 1643-1650. 1998.

REICHARDT, K.; LIBARDI, P.L.; SANTOS, J.M. dos. An analysis of soil-water movement in the field: II, water balance in a snap bean crop. Piracicaba: CENA/USP, 1974. 19p. (CENA. Boletim Científico, 22). 
RESENDE, M.; HENDERSON, D. W.; FERERES, E. Frequência de irrigação, desenvolvimento e produção do feijão kidney. Pesquisa Agropecuária Brasileira, v. 16, n. 3, p. 363-370, 1981.

ROSENBERG, N. J.; VERMA, S. B. Extreme evapotranspiration by irrigated alfafa: A consequence of the 1976 Midwestern Drought. Journal of Apllied Meteorology, v.17, p. 934-41, 1978.

SAAD, A. M. Uso do tensiômetro no controle da irrigação por pivô central em cultura do feijoeiro. Piracicaba, 1991. 141 p. Tese (Mestrado) - ESALQ/USP.

SEDIYAMA, G. C. Necessidade de água para os cultivos. Brasília: ABEAS, 1987. $143 p$.

SENTELHAS, P. C. Estimativa diária da evapotranspiração de rferência com dados de estação meteorológica convencional e automática. Piracicaba, 1998. 97p. Tese (Doutorado) - Escola Superior de Agricultura "Luiz de Queiroz", Universidade de São Paulo.

SHAW, R. H. A comparison of solar radiation and net radiation. Bulletim American Meteorology Society, v. 37, p. $205-206.1956$.

SILVA, E.L. Suscetibilidade do feijoeiro (Phaseolus vulgaris L.) cv. Goiano Precoce a inundações temporárias do sistema radicular em diferentes fases do seu ciclo vegetativo. Piracicaba, 1982. 76 p. Dissertação (Mestrado) - ESALQ/USP.

SILVA, F.C.; FOLEGATTI, M. V. MAGIOTTO, S. R. Análise do funcionamento de um lisímetro de pesagem com célula de carga. Revista Brasileira de Agrometeorologia, vol. 7, n. 1, p. 53-58, 1999. 
SINCLAIR, T. R.; ALLEN, Jr. L. H.; LEMON, E. R. An analysis of error in the calculation of energy flux densities above vegetation by a Bowen ratio profile method. Boundary-Layer Meteorology, vol. 8, p.129-139. 1975.

SMITH, M., ed. Report on the expert consultation on procedures for revision of FAO guidelines for predictions of crop water requirements. Rome: FAO, 1991. $45 p$.

SOUZA, J. L.; ESCOBEDO, J. F. Balanço de radiação em cultivos de feijão- vagem com e sem cobertura de polietileno. Pesquisa Agropecuária Brasileira. V. 32, n. 1, p. 1-15, 1997.

STANHILL, G. A comparasion of methods of calculatiing potential evapotranspiration from climatic data. Israel Journal Agriculture Resource, v. 11, p. 159-71, 1961.

STONE, L. F.; PORTES, T. DE A.; MOREIRA, J. A. A. Efeito da tensão de água do solo sobre a produtividade e crescimento do feijoeiro. II. Crescimento. Pesquisa Agropecuária Brasileira, v. 23, n. 5, p. 503-510, 1988.

TANNER, C. B. Energy balance approach to evapotranspiration from crops. Soil Science Society of America. Proceedings. Madison, vol. 24, n.1, p.1-9. 1960.

TANNER C. B.; PETERSON, A. E.; LOVE, J. R. Radiant energy exchange in a corn field. Agronomy Journal, v. 52, p. 373-379, 1960.

TANNER, C. B.; LEMON, E. R. Radiant energy utilized in evapotranspiration. Agronomy Journal, v. 54, n.3, p. 207-12, 1962.

THOM, A. S. Momentum, mass and heat exchange pf plant communities. In: MONTEITH, J. L. , ed. Vegetation and the atmosphere. London: Academic Press, 1975. v. 1 , cap. 3 , p. $57-109$. 
THOM, A. S.; OLIVER, H. R. On Penman's equation for estimating regional evaporation. Quartely Journal of the Royal Meteorological Society, v. 103, p. 345-57, 1977.

THORNTHWAITE, G. W. An approach toward a rational classification of climate. Geographycal Review., v. 38, n. 1, p. 55-94, 1948.

VIEIRA, C. Cultura do feijão. Viçosa: Imprensa Universitária, 1978. 146 p.

VIEIRA, C. Doenças e pragas do feijoeiro. Viçosa. UFV, 1988. 231 p.

VILLA NOVA, N. A. Estudos sobre o balanço de energia em cultura de arroz. Piracicaba., Escola Superior de Agricultura "Luiz de Queiroz", Universidade de São Paulo, 1973. 89p. Tese de Livre Docência.

VILLA NOVA, N. A. Principais métodos de estimativa de aplicação de água de irrigação. Piracicaba: ESALQ, Departamento de Física e Meteorologia, 1987. 22p.

VILLA NOVA, N. A.; REICHARDT, K. Evaporação e evapotranspiração. In: RAMOS, F.; OCCHIPINTI, A. G.;VILLA NOVA, N. A.; REICHARDT, K.; MAGALHÃES, P. C.; CLEARY, R. W. Engenharia hidrológica. Rio de Janeiro: ABRH, 1989. cap. 3, p. 145-97. (Coleção ABRH de Recursos Hídricos, 2)

VILLA NOVA , N. A.; SALATI, E.; MATSUI, E. Estimativa da evapotranspiração na Bacia Amazônica. Acta Amazonica, v. 6, n. 2, p. 215-58, 1976.

WHITE, J. W. Conceptos basicos de la fisiológia del frijol: guiá de estudio para ser usada como complemento de la unidade audiotutorial sobre el mismo tema. Colombia: CIAT, 1988. 58 p. (Serie: 04 5b-07.01)

YOSHIDA, S. Physiological aspects of grain yield. Annual review Plant Physiology, v. 23, p. 437-464, 1972. 